\title{
Seasonally variant low cloud adjustment over cool oceans
}

2
Youichi Kamae $^{1 *}$, Robin Chadwick², Duncan Ackerley ${ }^{3}$, Mark Ringer ${ }^{2}$, and Tomoo Ogura ${ }^{4}$

${ }^{1}$ Faculty of Life and Environmental Sciences, University of Tsukuba, Tsukuba, Ibaraki, Japan

${ }^{2}$ Met Office Hadley Centre, Exeter, Devon, UK

${ }^{3}$ Met Office, Exeter, Devon, UK

${ }^{4}$ National Institute for Environmental Studies, Tsukuba, Ibaraki, Japan

\section{Submitted to Climate Dynamics}

*Corresponding author: Youichi Kamae, Faculty of Life and Environmental Sciences, University of Tsukuba, 1-

1-1 Tennoudai, Tsukuba, Ibaraki 305-8572, Japan (kamae.yoichi.fw@u.tsukuba.ac.jp), Tel.: +81-29-853-4755 Fax: +81-29-853-6709 


\section{Abstract}

The Earth's solar reflectance is reduced through rapid climate adjustments to increasing $\mathrm{CO}_{2}$, via a decrease

in total cloud cover over ocean. Perturbations to marine boundary-layer clouds are essentially important for the

global radiative balance at the top of the atmosphere. However, the physical robustness of low cloud adjustments

to increasing $\mathrm{CO}_{2}$ has not been assessed systematically. Here we show that low cloud adjustment is distinct from

that in total cloud and is seasonally variant. Among multiple climate models, marine boundary-layer clouds over

the subtropics and extratropics (especially over the Northern Hemisphere) are consistently increased in the rapid adjustment, while middle and high clouds are greatly reduced. The increase in low cloud cover is only found during summer, associated with a summertime enhancement of lower tropospheric stability. We further examine mechanisms behind the rapid adjustments of low cloud and inversion strength of the boundary layer, using land surface temperature prescribing experiments in an atmospheric general circulation model (AGCM). Summertime increases in low cloud and enhanced inversion strength over the ocean simulated in this AGCM are attributed to (1) $\mathrm{CO}_{2}$-induced land warming; and (2) reduced radiative cooling in the lower troposphere due to increased $\mathrm{CO}_{2}$. The seasonality in the cloud adjustment implies an importance of seasonal variations in background cloud and atmospheric circulation related to the Hadley and monsoon circulations for radiative forcing, feedback and climate sensitivity.

Keywords: Cloud adjustment, instantaneous radiative forcing, inversion strength, low cloud 


\section{Introduction}

Cloud responses to external forcing (e.g. greenhouse gases and aerosols) imposed on the Earth's climate

system are very important for perturbing the radiative balance at the top of the atmosphere (TOA) and surface air temperature (SAT). Clouds are the major source of uncertainty in estimating climate sensitivity, determined as global-mean SAT increase in response to doubling of atmospheric $\mathrm{CO}_{2}$ concentration (e.g. Cess et al. 1989; Boucher et al. 2014; Bretherton 2015; Kamae et al. 2016a; Ceppi et al. 2017). By using numerical model simulations, uncertainty in cloud response to $\mathrm{CO}_{2}$ increases can be divided into two processes: fast cloud adjustment to increasing $\mathrm{CO}_{2}$; and slow cloud response mediated by global-mean SAT increase (Gregory and Webb 2008; Andrews et al. 2012; Kamae et al. 2015; Sherwood et al. 2015). There are large uncertainties across different climate models for both processes (e.g. Vial et al. 2013; Webb et al. 2013; Zelinka et al. 2013). Previous studies found that cloud adjustment and cloud feedback are anticorrelated among climate models, which is important for the resultant uncertainty spread in climate sensitivity (Shiogama et al. 2012; Webb et al. 2013; Ringer et al. 2014). Chung and Soden (2018) demonstrated that marine boundary-layer cloud is the key for the adjustment-feedback compensation among multiple models that participated in the Coupled Model Intercomparison Project phase 5 (CMIP5; Taylor et al. 2012). However, physical mechanisms responsible for the compensation of cloud adjustment and feedback are still unclear and further work is required to reduce the uncertainty.

Previous studies demonstrated that the key processes responsible for tropospheric cloud adjustments are: the land-sea warming contrast related to the land response to increased $\mathrm{CO}_{2}$ (Dong et al. 2009; Wyant et al. 2012;

Kamae and Watanabe 2013; Chadwick et al. 2014); tropospheric warming and resultant drying (Kamae and 
Watanabe 2012; Kamae et al. 2015); and enhanced stability in lower troposphere due to tropospheric warming (Webb et al. 2013; Ogura et al. 2014; Qu et al. 2015a). $\mathrm{CO}_{2}$-induced land warming found in atmospheric general circulation model (AGCM) simulations with prescribed sea surface conditions (temperature and sea ice) changes the large-scale atmospheric circulation and induces tropospheric warming (Chadwick et al. 2014; He and Soden 2015, 2016; Shaw and Voigt 2015, 2016), which are important for cloud adjustments over land and ocean (Colman and McAvaney 2011; Kamae and Watanabe 2012, 2013; Kamae et al. 2015). The land surface and atmosphere above are also greatly influenced by the plant physiological response to imposed $\mathrm{CO}_{2}$ forcing (reduced evapotranspiration due to stomatal closure; e.g. Boucher et al. 2009; Doutriaux-Boucher et al. 2009; Abe et al. 2015), leading to reduced cloud cover over land (Andrews et al. 2012).

In addition to the land-mediated cloud responses, perturbations to the atmospheric radiative heating profile due to increased $\mathrm{CO}_{2}$ is also critically important for the cloud adjustment (see Fig. S1). Longwave radiative heating (i.e. reduced radiative cooling of the troposphere; Sugi and Yoshimura 2004; Collins et al. 2006; Colman and McAvaney 2011; Kamae and Watanabe 2013; Ogura et al. 2014; Merlis 2015) due to instantaneous radiative forcing of $\mathrm{CO}_{2}$ (Hansen et al. 2002) results in a shoaling of the planetary boundary layer (e.g. Watanabe et al. 2012; Wyant et al. 2012; Bretherton et al. 2013; Kamae and Watanabe 2013; Zelinka et al. 2013) and reduction of total cloud amount over the ocean, then increases effective radiative forcing of $\mathrm{CO}_{2}$ via the tropospheric adjustment (Kamae and Watanabe 2012; Bretherton et al. 2013; Zelinka et al. 2013; Kamae et al. 2015). However, modeled low-cloud adjustment still shows a large spread among different modeling studies (Wyant et al. 2012; Bretherton 
et al. 2014; Kamae et al. 2015; Blossey et al. 2016; Xu et al. 2018), suggesting uncertainty in the relative importance of the physical processes discussed above.

One of the key limitations in our understanding of the cloud adjustment to imposed $\mathrm{CO}_{2}$ forcing is due to the difficulty in decomposing the adjustment into individual processes including atmospheric radiation, land warming, and the plant physiological response. Shine et al. (2003) conducted a set of prescribed land temperature experiments in an intermediate complexity GCM to estimate radiative forcing and climate sensitivity. In contrast to fixed sea surface temperature (SST) simulations in AGCMs, such prescribed land temperature experiments are useful to evaluate the effective radiative forcing independently from land surface warming. However, this method has not been widely applied to the CMIP ensembles due to the technical difficulty in prescribing land surface temperatures. Recently, Ackerley and Dommenget (2016) proposed a new method for decomposing the effects of instantaneous radiative forcing, increases in SST, increases in land surface temperature, and the plant physiological response from conventional AGCM simulations. Under this framework, Ackerley et al. (2018) conducted a suite of AGCM simulations and made their output available for facilitating wider studies including those focusing on atmospheric circulations and rainfall patterns (Chadwick et al. 2018). In our study, we aim to examine the physical processes that control robust and uncertain parts of the cloud adjustment to increasing $\mathrm{CO}_{2}$ by using the prescribed land surface temperature simulations described in Ackerley et al. (2018). Results from these simulations clearly show seasonal difference in the cloud and tropospheric temperature responses to seasonally-uniform $\mathrm{CO}_{2}$ increases, which is very important for the seasonal migration of the Intertropical Convergence Zone (ITCZ) and monsoons (Kamae et al. 2014, 2016b; Shaw and Voigt 2015; Chen and Bordoni 2016; Chadwick et al. 2018). Seasonal 
variations found here improve process-based understanding of cloud adjustments. Section 2 describes the data and methods including multiple model simulations and prescribed land surface temperature experiments in an AGCM.

Section 3 compares cloud adjustments among different models, vertical levels and seasons. Section 4 provides results of a decomposition of low cloud adjustment using a set of AGCM simulations. In Section 5, we discuss possible reasons for the seasonal variation in cloud adjustment to a seasonally-uniform increase in $\mathrm{CO}_{2}$ concentration. Section 6 is a summary with discussion.

\section{Data and methods}

\subsection{CMIP5 model simulations}

To examine the robustness of cloud adjustments, we use the results of multiple model simulations conducted under CMIP5 (Taylor et al. 2012). We use results from sstClim and sstClim4xCO2 runs conducted in 15 AGCMs (Table S1). The rapid adjustments of lower tropospheric stability and low cloud fraction over ocean found in these AGCM-based simulations are consistent with those found in atmosphere-ocean coupled model simulations forced by abruptly increased $\mathrm{CO}_{2}$ concentration (e.g. Kamae and Watanabe 2013; Kamae et al. 2015; Qu et al. 2015a). In sstClim, AGCMs were driven by climatological SSTs and sea-ice concentrations derived from pre-industrial control simulations in each model. Boundary conditions for sstClim4xCO2 are identical to sstClim except for atmospheric $\mathrm{CO}_{2}$ concentration (280 and 1120 ppmv in sstClim and sstClim4xCO2, respectively). In this study, we examine differences ( $\Delta$ hereafter) of climatology (averaged over 30 years) between the two simulations. 
at each model layer (note that the number of model layers are different across models; see Table S1). The CMIP5 data portal did not archive diagnostics of low, middle and high cloud fraction. In this study, we approximate low, middle and high cloud fraction $\left(C_{\mathrm{l}}, C_{\mathrm{m}}\right.$ and $C_{\mathrm{h}}$ respectively) as the maximum cloud fraction between the surface and $780 \mathrm{hPa}, 780$ and $440 \mathrm{hPa}$, and 440 and $50 \mathrm{hPa}$, respectively. Although previous studies assessed $C_{1}$ by maximum cloud fraction between the surface and $680 \mathrm{hPa}$ (Noda and Satoh 2014; Zhou et al. 2016), we selected the boundary of $780 \mathrm{hPa}$ to emphasize the response of marine boundary-layer cloud over cool oceans (e.g. Norris 1998; Luo et al. 2016). Note that $\Delta C_{1}$ is not sensitive to choices of upper boundary criterion (e.g. $680 \mathrm{hPa}$ or 800 $\mathrm{hPa}$ ) because the near-surface (below $850 \mathrm{hPa}$ level) response dominates the low cloud adjustment (see sect. 3.1).

\subsection{AMIP simulations with prescribed land surface temperature}

In addition to CMIP5 model ensemble, we use the results of prescribed land surface temperature simulations conducted in an AGCM, ACCESS1.0 (Bi et al. 2013; Frauen et al. 2014). Details of model configuration and experimental setup are found in Ackerley and Dommenget (2016) and Ackerley et al. (2018). Simulated data are available from Ackerley (2017). Here we briefly describe the experimental framework and decomposition methods. ACCESS is configured similarly to the Hadley Centre Global Environmental Model version 2 (HadGEM2: Martin et al. 2011). The version of ACCESS1.0 used here has a horizontal resolution of $3.75^{\circ}$ longitude and $2.5^{\circ}$ latitude and 38 vertical levels. The timestep of the model integration is 30 minutes. The AGCM includes physics parameterizations (precipitation, cloud, convection, radiative transfer, boundary layer and aerosols) and is coupled 
with a land surface parameterization (Cox et al. 1999; Essery et al. 2001). Soil moisture and temperature are simulated over four vertical layers $(0.1,0.25,0.65$ and $2 \mathrm{~m}$ depth $)$.

To examine physical mechanisms responsible for rapid adjustment, we use AGCM runs with free-varying land condition (free runs) and prescribed land surface temperature experiments (PL runs). All the simulations are driven by observed SST and sea ice fraction from 1979 to 2008. In this study, the climatology of the last 25 years out of the 30 -yr integration is examined. Free runs with $\mathrm{CO}_{2}$ concentrations of 346 and $1384 \mathrm{ppmv}$ are referred as A and A4x, respectively. Here prescribed SST is not identical to that used in CMIP5 sstClim run (model climatology; sect. 2.1), but the SST difference doesn’t substantially affect results of this study (not shown). In A4xrad, the radiation code uses $\mathrm{CO}_{2}$ concentration of $1384 \mathrm{ppmv}$ but the vegetation uses $346 \mathrm{ppmv}$ in order to isolate the effect of the plant physiological response (Boucher et al. 2009; Doutriaux-Boucher et al. 2009). Instantaneous values of the surface temperature, soil temperature and moisture (on each soil level) in these runs are stored every three hours. In the PL runs, the stored land conditions are read in by the model every three hours and updated (by interpolation) every hour. In A4xradpL run, for example, land surface conditions are replaced by those simulated in $\mathrm{A}$ run but only the radiation code refers to a $\mathrm{CO}_{2}$ concentration of 1384 ppmv. If we compare the results of A4xradPL and $A_{P L}$ runs, the difference indicates the effect of atmospheric radiative heating rate due to $\mathrm{CO}_{2}$ quadrupling without any effects of perturbations in land conditions (RAD_ATM; Table 1). Similarly, the effect of the plant physiological response (PLANT), the effect of land warming due to atmospheric radiative perturbation (RAD_LAND), and a residual (RES) are calculated by comparing free and PL runs (Table 1; see also Fig. S1). Note that interpolated land surface conditions are updated every hour instead of every 30 minutes (the 
timestep of model integrations). Therefore, the results of PL runs are not strictly identical to free runs (see Ackerley et al. 2018 for detail). We checked the residual term due to this difference, but it does not affect our results substantially (see Figs. S2, S3 and Supplementary Discussion).

\section{Seasonality in cloud adjustment in CMIP5 models}

We first examine the robustness of cloud adjustments and its seasonal variation across CMIP5 models.

Figure 1a-c shows the 15-model ensemble mean of annual-mean cloud adjustment over the ocean. As demonstrated in previous studies (Kamae and Watanabe 2012; Zelinka et al. 2013; Vial et al. 2013; Kamae et al. 2015), global-mean total cloud amount tends to decrease (with weak increase over several regions including the North Pacific; Fig. 1a), leading to an enhancement of effective radiative forcing of $\mathrm{CO}_{2}$ via reduction of shortwave reflection due to clouds. Kamae and Watanabe (2013) concluded that this anomalous shortwave component of cloud radiative effect is due to low cloud reduction from simulations based on an AGCM. However, if we decompose the multi-model cloud adjustment into different vertical levels (sect. 2.1), it is clearly found that the annual-mean cloud reduction dominates in the middle and upper troposphere rather than the lower troposphere

(Fig. 1b, c). The model-simulated cloud fraction below the $780 \mathrm{hPa}$ level is increased over subtropical low cloud regions, including California and the Canary Islands, and the extratropical Northern Hemisphere. The $27^{\circ} \mathrm{C} \mathrm{SST}$ isotherm is shown in these panels as an approximation of the boundary between tropical deep convective region and subtropical atmospheric subsidence regions (Zhang 1993; Sud et al. 1999). In contrast to the anomalous low cloud cover over the subtropics, such cloud adjustments are not consistently found in the total cloud amount in the 
subtropics (Fig. 1a), suggesting greater contributions from middle and high clouds than low cloud. The increase in low-cloud cover in annual-mean field is clearly found over cool SST $\left(<27^{\circ} \mathrm{C}\right)$ regions over the Northern Hemisphere but is not apparent over the Southern Hemisphere (Fig. 1c).

In the fixed-SST increased- $\mathrm{CO}_{2}$ simulations, changes in boundary-layer inversion strength is a major factor for the low cloud response (Klein and Hartmann 1993; Qu et al. 2015b; Myers and Norris 2016; Kawai et al. 2017).

Figure 2 shows anomalies in SAT, air temperature at the $700 \mathrm{hPa}$ level $\left(T_{700}\right)$, and estimated inversion strength (EIS; Wood and Bretherton 2006) in response to quadrupling $\mathrm{CO}_{2}$. Here a given EIS response ( $\Delta$ EIS) can be approximated by a linear combination of $\Delta \mathrm{SAT}$ and $\Delta T_{700}$ (see Qu et al. 2014, 2015a for detail). In the fixed-SST simulations, $\Delta T_{700}$ dominates $\Delta$ EIS because of little $\Delta$ SAT (Fig. 2). In response to increasing $\mathrm{CO}_{2}$, the lower troposphere warms up through radiative heating due to instantaneous $\mathrm{CO}_{2}$ radiative forcing (e.g. Sugi and Yoshimura 2004; Collins et al. 2006; Kamae and Watanabe 2013) and the effect of land warming (e.g. Chadwick et al. 2014; Kamae et al. 2014), resulting in positive $\Delta$ EIS over ocean (Webb et al. 2013; Qu et al. 2015a). This enhanced inversion is especially dominant over the extratropical North Pacific and subtropical low-cloud regions (off the coasts of California and the Canary Islands; Fig. 2c) but relatively weak over warm oceans (see SST contours in Fig. 1c), consistent with $\Delta C_{1}$ (Fig. 1c). Table 2 summarizes area-averaged $\Delta C$ and $\Delta E I S$. In contrast to strong and robust reductions of $C_{\mathrm{h}}$ and $C_{\mathrm{m}}$ (and resultant $C_{\mathrm{t}}$ ), annual-mean $C_{1}$ shows increases (no changes) over the low-cloud regions (cool ocean) with large inter-model spreads (see Figs. S4, S5 and S6).

The weak annual-mean $\Delta C_{1}$ can be understood as a result of seasonal compensation. Figure $1 \mathrm{~d}-\mathrm{i}$ show wintertime and summertime cloud adjustment. Here winter (summer) is determined by November-to-March mean 
and May-to-September mean over the Northern (Southern) and Southern (Northern) Hemispheres, respectively.

While $\Delta C_{\mathrm{h}}+\Delta C_{\mathrm{m}}$ is largely consistent between the two seasons (reduction over extratropics; Fig. 1e, h), CMIP5 models consistently show clear seasonality in the low cloud adjustment: general decrease in winter but greater increases over the subtropics and extratropics in summer (Figs. 1f, i, S6). The large increase in the summertime Northern Hemisphere is also found in the total cloud adjustment (Fig. 1g), contributing to the increase in $C_{\mathrm{t}}$ in some regions in the annual-mean field (Fig. 1a). The effect of $\Delta C_{1}$ on $\Delta C_{\mathrm{t}}$ suggests an important contribution to radiative balance at TOA (i.e. effective radiative forcing). Table 3 summarizes seasonal variation in the response of the shortwave cloud radiative effect (SWcld) to quadrupling $\mathrm{CO}_{2}$ in CMIP5 models. Here, SWcld is simply calculated by taking the difference between all-sky radiation and clear-sky radiation at TOA that includes the cloud masking effect (Soden et al. 2004, 2008). Note that the cloud masking effect on the shortwave component of cloud adjustment is much smaller than that on the longwave component (Wyant et al. 2012; Kamae et al. 2015). Positive $\Delta \mathrm{SWcld}$ is consistently simulated in 15 models in all seasons. Over cool oceans, summertime $\Delta \mathrm{SWcld}$ is weaker than that in winter, consistent with summertime increment of $C_{1}$ (and seasonal variation of $\Delta C_{\mathrm{t}}$ ) over the subtropics and extratropics (Fig. 1i). However, the effects of seasonally-variant $\Delta C_{1}$ on $\Delta C_{\mathrm{t}}$ and $\Delta \mathrm{SWcld}$ are relatively limited compared to those of $\Delta C_{\mathrm{h}}$ and $\Delta C_{\mathrm{m}}$ (Tables 2, 3, Fig. 1).

Figure 3 compares zonal-mean $\Delta \mathrm{EIS}$ and $\Delta C_{1}$ averaged over cool oceans ( $\mathrm{SST}<27^{\circ} \mathrm{C}$ ). In contrast to small or negative $\Delta C_{1}$ during winter, summertime positive $\Delta C_{1}$ is consistently found in 15 CMIP5 models (Table 2, Figs. 1i, 3b, S6). The seasonal variation (summertime enhancement) is also consistently found in $\Delta$ EIS (Table 2, Figs. 2f, i, 3a) and $\Delta T_{700}$ (Fig. 2e, h), and is larger over the Northern Hemisphere than the Southern Hemisphere. Possible 
reasons for the seasonal variations in temperature and $\Delta \mathrm{EIS}$ and their interhemispheric differences are discussed in the next section. Seasonal variation (summer minus winter) in $\Delta$ EIS and $\Delta C_{1}$ shown in Fig. 4 is closely related each other: neutral or partly negative over the tropics $\left(20^{\circ} \mathrm{S}-20^{\circ} \mathrm{N}\right)$ but positive and large over subtropics and extratropics especially over the North Pacific and low cloud regions off the coasts of California and the Canary Islands. This spatial coherence (correlation coefficient is 0.56 ) indicates that the seasonal variation in $\Delta C_{1}$ is largely controlled by that in lower tropospheric warming (and resultant $\Delta \mathrm{EIS}$ ).

\section{Decomposition of cloud adjustment}

In the previous section, we demonstrated that low cloud adjustment over cool oceans exhibits a seasonal reversal and is consistently found among CMIP5 models. The summertime increase in $C_{1}$ is likely to be related to summertime enhancement of lower tropospheric warming and resultant positive $\Delta$ EIS. From Fig. 2, larger land surface warming during summer than winter is a possible reason for the seasonal variations in lower tropospheric temperature and $C_{1}$. To examine physical mechanisms in detail, we further use outputs from prescribed land surface temperature experiments conducted in ACCESS1.0 (sect. 2.2). Before we decompose the cloud adjustment, we compare adjustments of temperature, EIS and cloud fraction in this model with results from the CMIP5 ensemble. Figure 5 shows annual-mean cloud adjustment and temperature response. Table 4 summarizes annual-mean responses averaged over cool oceans. As found in CMIP5 models (Figs. 1, 2), the land surface and lower troposphere warm up in response to increasing $\mathrm{CO}_{2}$, resulting in a general increase in EIS (Table 4) especially over the subtropics and extratropics (Fig. 5a-c). The enhanced EIS is consistent with increased $C_{1}$ over cool oceans, in 
contrast to large decreases in $C_{\mathrm{h}}$ and $C_{\mathrm{m}}$ (Table 4, Fig. 5e, f). The $C_{1}$ increase simulated in ACCESS1.0 is generally larger than CMIP5 multi-model mean (Tables 2, 4). Among CMIP5 models, both the strength and spatial pattern of $\Delta C_{1}$ exhibit large inter-model spreads (Table 3, Fig. 3b; see Fig. S5). However, increased $C_{1}$ in the North Pacific (and other regions with large low-cloud fractions) and their seasonal variations found in CMIP5 models (Figs. 1, 3) are consistently simulated in ACCESS1.0 (Fig. 5; detailed below). Thus, we examine the physical mechanisms responsible for the seasonal variation of $C_{1}$ adjustment by using the sensitivity simulations conducted in this model.

Figures 6 and 7 show decompositions of $C_{\mathrm{l}}, C_{\mathrm{m}}$ and $C_{\mathrm{h}}$ adjustment to quadrupling $\mathrm{CO}_{2}$ based on ACCESS1.0 sensitivity simulations detailed in sect. 2.2. The increase in annual-mean $C_{1}$ (Fig. 5f) is almost entirely explained by the sum of two comparable contributions: RAD_ATM and RAD_LAND effects (Fig. 6a, c; see Table 1). The effect of RAD_ATM results in a general increase in $C_{1}$ over cool oceans in both hemispheres, while the RAD_LAND effect is more dominant over the Northern Hemisphere than the Southern Hemisphere. It should also be noted that effects of RES on $\Delta C_{1}$ and $\Delta C_{\mathrm{h}}+\Delta C_{\mathrm{m}}$ are not negligible (sect. 2.2; Figs. S2, S3; see Supplementary Discussion). The characteristics of effects of RAD_ATM and RAD_LAND are consistent with $\triangle E I S$ shown in Fig. 8. In response to increasing $\mathrm{CO}_{2}$, the perturbation in longwave radiative heating rate due to instantaneous radiative forcing warms the lower-to-upper troposphere (Kamae and Watanabe 2013; Ogura et al. 2014) with its peak at the 700-850 hPa level (Sugi and Yoshimura 2004; Collins et al. 2006). The radiative heating results in enhanced lower tropospheric stability over most of the oceans (Fig. 8a). Possible reasons for spatial pattern of the lowertropospheric warming are discussed in sect. 5. The effect of RAD_LAND, in contrast, is strongest over the subtropics and extratropics (especially over the North Pacific; Fig. 8c) with its peak at middle and upper 
troposphere (not shown). The stronger effect of RAD_ATM than RAD_LAND over the subtropics and extratropics

is consistent with relative strength of their effects on $C_{1}$ (Fig. 6a, c). The enhanced stability over the subtropics and extratropics (Figs. 2c, 5c) can be understood as a result of a combined effect of RAD_ATM and RAD_LAND. The effect of PLANT negatively contributes to the responses of EIS and $C_{1}$ (Figs. 6b, 8b), which resulted from changes in land surface heat and moisture budgets. The stomatal closure from higher $\mathrm{CO}_{2}$ concentration causes a decrease in evapotranspiration, an increase in the sensible heat flux, and surface warming over tropical land (e.g. Dong et al. 2009; Andrews and Ringer 2014; DeAngelis et al. 2016). The land surface warming in addition to the decreased evapotranspiration partly affects EIS (Dong et al. 2009) and $C_{1}$ over ocean; however, the total contributions of PLANT are minor compared to RAD_ATM and RAD_LAND (Table 4, Fig. S2a, c; see Supplementary Discussion). Which effect dominates the seasonal variation in cloud adjustment? To answer this question, we examine wintertime and summertime temperature and $C_{1}$ adjustment. As shown in Fig. 9, both RAD_ATM and RAD_LAND effects act to warm the lower troposphere both in winter and summer (Fig. 9a, d, g, j). However, wintertime warming is generally weaker than that during summer, resulting in seasonal variations in $\Delta \mathrm{EIS}$ and $\Delta C_{1}$

(Fig. 9b, c, e, f, h, i, k, l). Both RAD_ATM and RAD_LAND effects result in positive $\Delta C_{\mathrm{t}}$ due to large positive $\Delta C_{1}$ during summer, in contrast to small positive $\Delta C_{1}$ during winter (Table 4). Note that the sign and magnitude of $\Delta C_{\mathrm{t}}, \Delta C_{\mathrm{h}}+\Delta C_{\mathrm{m}}$, and $\Delta C_{1}$ simulated in ACCESS1.0 (e.g. wintertime positive $\Delta C_{1}$ over the Southern Hemisphere middle latitude; Fig. S7f) are partly different from CMIP5 multi-model mean (Tables 2, 3, 4, Figs. 1, 2, 5d-f) but seasonal contrasts (summer minus winter) in $\Delta \mathrm{SAT}, \Delta T_{700}, \Delta \mathrm{EIS}$, and $\Delta C_{1}$ are generally consistent with the model ensemble mean (see Figs. S7, S8). Figure 10 compares seasonal-mean zonal-mean adjustments due to the effects 
of RAD_ATM and RAD_LAND. Both effects result in strong warming in summer over the subtropics and extratropics with its peak over $50^{\circ} \mathrm{S}-40^{\circ} \mathrm{S}$ and $40^{\circ} \mathrm{N}-50^{\circ} \mathrm{N}$ (Fig. 10a, c). Seasonal $\Delta C_{1}$ is rather noisy compared to $\Delta$ EIS, but seasonal contrasts are similarly found (Fig. 10b, d) and are consistent with the total adjustment simulated in CMIP5 models (Fig. 3). Seasonal contrasts in $\Delta C_{1}$ and $\Delta$ EIS due to the RAD_LAND effect are consistently larger over the Northern Hemisphere than the Southern Hemisphere (Fig. 10c, d). Such interhemispheric differences can also be found in CMIP5 ensemble (Fig. 3), suggesting that the stronger low cloud adjustments over the Northern Hemisphere than the Southern Hemisphere are attributed to the land effect.

\section{Possible reasons for the seasonal variation}

The low-cloud adjustment consistently dominates during summer among the CMIP5 models. Sensitivity tests using ACCESS1.0 indicate that the seasonally-variant low-cloud adjustment can be attributed to seasonality

in the response of inversion strength to increasing $\mathrm{CO}_{2}$, which itself is a response to both through atmospheric radiative perturbation and radiative land warming. A remaining question addressed here is: what is the physical reason for the seasonal difference in lower tropospheric warming despite seasonally-uniform $\mathrm{CO}_{2}$ increments?

One possible factor is a dynamic contribution: the effect of atmospheric circulation response to increasing $\mathrm{CO}_{2}$.

Bony et al. (2013) suggested that $\mathrm{CO}_{2}$ forcing may slow the tropical atmospheric circulation including Hadley and

Walker circulations because $\mathrm{CO}_{2}$-induced longwave heating (weakened radiative cooling; e.g. Sugi and Yoshimura 2004; Collins et al. 2006) especially over dry subsiding regions possibly change the tropical overturning circulation strength. Merlis (2015) further showed that clear-sky $\mathrm{CO}_{2}$ forcing reduces tropical atmospheric circulation 
281

282

intensity via reduction of radiative cooling. Such changes in large-scale atmospheric circulation possibly result in tropospheric temperature changes through vertical advection and adiabatic compression.

Figure 11 shows the response of vertical temperature advection and adiabatic compression to quadrupling $\mathrm{CO}_{2}$ via RAD_ATM effect. Changes in vertical pressure velocity at the $700 \mathrm{hPa}$ level $\left(\Delta \omega_{700}\right)$ are generally opposite to the climatological $\omega_{700}$ (Fig. 11a, c), indicating the weakening of atmospheric circulation. Over convective regions, positive $\Delta \omega_{700}$ (anomalous subsidence) are consistently found over the both hemispheres. The anomalous subsidence results in warming (warm advection) because potential temperature is larger at higher altitude than lower altitude. Inversely, a cooling effect dominates over climatological subsidence regions including off the coasts of California and the Canary Islands, as a result of anomalous ascending motion (Fig. 11b, d). These spatial patterns and zonal-mean heating rate (Fig. 11e) are not similar to those in lower-tropospheric warming and $\Delta$ EIS resulted from the RAD_ATM effect (Figs. 9, 10).

Another possible factor is seasonality in $\mathrm{CO}_{2}$ instantaneous radiative forcing. Huang et al. (2016) revealed that instantaneous radiative forcing of spatially uniform increment of $\mathrm{CO}_{2}$ is not spatially uniform because of spatial patterns of (1) surface temperature, (2) upper-level (10 hPa) atmospheric temperature, and (3) column water vapor content. Similarly, instantaneous radiative forcing could be seasonally non-uniform. To test this point, we examine instantaneous radiative forcing of $\mathrm{CO}_{2}$ provided by five climate models: CanAM4, HadGEM2-A, IPSLCM5A-LR, MIROC3, and MIROC5. Although this diagnostic is not available for ACCESS1.0, spatial patterns and seasonal variation in this model are likely to be very similar to those in HadGEM2-A, due to the almost identical model formulation (see sect. 2.2). Figure 12 compares the simulated radiative (shortwave and longwave) 
heating at the $700 \mathrm{hPa}$ level due to instantaneous $\mathrm{CO}_{2}$ forcing between the two seasons. Instantaneous radiative forcing is stronger over lower latitudes than higher latitudes because higher SAT results in stronger forcing (Huang et al. 2016). In addition, instantaneous radiative forcing over ITCZ is weaker than surrounding subtropical regions because of more water vapor content (Merlis 2015). These two factors also determine the seasonal variation in instantaneous radiative forcing. The climate models examined here consistently show stronger radiative heating over the subtropics and extratropics (except for the eastern tropical Pacific in MIROC5 model) during summer than winter (Fig. 12). Note that instantaneous radiative forcing simulated in MIROC3 is distinct from other models due to difference in the radiative calculation as reported in Ogura et al. (2014). Except for the wet convective regions (SST $>27{ }^{\circ} \mathrm{C}$ ), the summertime heating rate over cool oceans is stronger than winter, consistent with stronger $\Delta T_{700}$ and $\Delta$ EIS (Fig. 9). The stronger heating rate is consistent with higher SAT during summer than winter. In the fixed-SST simulations, SAT should be higher during summer than winter due to higher SST and seasonal variation in incoming solar radiation. As a result, seasonal variations in SAT, instantaneous radiative forcing, $\Delta T_{700}, \Delta \mathrm{EIS}$, and $\Delta C_{1}$ (stronger instantaneous radiative forcing during summer results in larger increase in $C_{1}$ than winter) should be consistent among different climate models (Figs. 1, 2, 12, S6). Note that near-surface instantaneous radiative forcing is also perturbed due to increased $\mathrm{CO}_{2}$ (figure not shown), but prescribed SST damps the near-surface temperature response to radiation (Fig. $1 \mathrm{~g}-\mathrm{i}$ ), resulting in the dominant contribution of the radiative heating at the $700 \mathrm{hPa}$ level (Fig. 12) to $\Delta \mathrm{EIS}$ (Figs. 8-10).

\section{Summary and discussions}


the Northern Hemisphere in the rapid adjustment to increasing $\mathrm{CO}_{2}$ in contrast to largest decreases in middle and

high clouds. In response to $\mathrm{CO}_{2}$ forcing, reduced radiative cooling in the lower troposphere together with land

surface warming induces lower tropospheric warming, resulting in enhanced inversion strength of the boundary

layer and increased low cloud over cool oceans. The enhanced inversion strength and low cloud increase are consistently amplified during summer in the both hemispheres. By examining a set of prescribed land surface

temperature experiments in an AGCM, the effects of atmospheric radiative heating, radiative land warming, the plant physiological response, and residual term of the low cloud adjustment are evaluated. The effects of atmospheric radiative heating and radiative land warming are comparably important for the low cloud adjustment over cool oceans. During summer, higher climatological SAT results in stronger instantaneous radiative forcing of

$\mathrm{CO}_{2}$ than winter despite a seasonally-constant increment of $\mathrm{CO}_{2}$ concentration. As a result, radiative warming of the lower troposphere and land surface are amplified during summer, resulting in a stronger enhancement of inversion strength and low-cloud increase over ocean than in winter. The present study relates seasonal variations in climatological SAT, EIS adjustment, and low-cloud adjustment. area, have implications for climate sensitivity. In most previous studies on cloud adjustment and climate sensitivity, the response of cloud cover was examined in the annual mean. This averaging procedure doesn't matter for the tropics, in which the seasonal cycle doesn't dominate. Over the subtropics and extratropics, in contrast, incoming 
$243 \mathrm{~W} \mathrm{~m}^{-2}$ in November-to-March in EQ- $90^{\circ} \mathrm{N}$ average). Over these regions, large seasonal variations can also be found in climatological SAT, atmospheric circulation, and cloud cover. The seasonal reversal of climatological atmospheric circulation and associated variations in precipitation and cloud cover are very important when we try to understand physical mechanisms responsible for their responses to external forcing. For example, their response to climate warming over tropical-to-subtropical land regions are substantially controlled by climatological monsoon circulations (Kamae et al. 2016b). The results of the present study imply that we need to examine the seasonal dependence of cloud feedbacks (e.g. Colman 2003; Taylor et al. 2011) over the subtropics and extratropics to external forcing as well as cloud adjustment. Chung and Soden (2018) identified that inter-model spreads of cloud adjustment and feedback are significantly anticorrelated through marine boundary-layer clouds. It should also be noted that rapid adjustments of cloud optical depth in addition to cloud fraction were also suggested as important factors for the total spread of cloud adjustment among climate models (Zelinka et al. 2013). Further investigations focused on seasonal variations in cloud adjustment and feedback, their relationship, and underlying physical mechanisms may improve our understanding of uncertainty and possible constraints on climate sensitivity.

\section{Acknowledgements}

We acknowledge the World Climate Research Programme's Working Group on Coupled Modeling, which is responsible for CMIP, and we thank the climate modeling groups (listed in Table S1 in the online supplement) for producing and making available their model output. For CMIP5, the US Department of Energy's Program for

Climate Model Diagnosis and Intercomparison provided coordinating support, and led the development of the 
software infrastructure in partnership with the Global Organization for Earth System Science Portals. This work was supported by JSPS KAKENHI Grant Numbers 17K14388 and 17K05657, and the Integrated Research

Program for Advancing Climate Models (TOUGOU program) from the Ministry of Education, Culture, Sports,

Science and Technology (MEXT), Japan. We would like to acknowledge M. Watanabe and H. Shiogama for helpful

discussions.

\section{References}

Abe M, Shiogama H, Yokohata T, Emori S, Nozawa T (2015) Asymmetric impact of the physiological effect of carbon dioxide on hydrological responses to instantaneous negative and positive $\mathrm{CO}_{2}$ forcing. Clim Dyn $45: 2181-2192$

Ackerley D (2017) AMIP ACCESS 1.0 prescribed land experiment collection v1.0: PLAMIP. NCI National Research Data Collection, https://researchdata.ands.org.au/prescribed-land-amip-experimentscollection/940117, https://doi.org/10.4225/41/59521137d6c42, accessed: 15-03-2018.

Ackerley D, Dommenget D (2016) Atmosphere-only GCM (ACCESS1.0) simulations with prescribed land surface 5 temperatures. Geosci Model Dev 9:2077-2098

Ackerley D, Chadwick R, Dommenget E, Petrelli P (2018) An ensemble of AMIP simulations with prescribed land surface temperatures. Geosci Model Dev Discuss. doi:10.5194/gmd-2018-77

Andrews T, Ringer MA (2014) Cloud feedbacks, rapid adjustments, and the forcing-response relationship in a transient $\mathrm{CO}_{2}$ reversibility scenario. J Clim 27:1799-1818

Andrews T, Gregory JM, Forster PM, Webb MJ (2012) Cloud adjustment and its role in $\mathrm{CO}_{2}$ radiative forcing and climate sensitivity: A review. Surv Geophys 33:619-635

Bi D, Dix M, Marsland SJ, et al. (2013) The ACCESS coupled model: description, control climate and evaluation. Aust Meteorol Ocean J 63:41-64

Blossey PN, Bretherton CS, Cheng A, Endo S, Heus T, Lock AP, van der Dussen JJ (2016) CGILS Phase 2 LES intercomparison of response of subtropical marine low cloud regimes to $\mathrm{CO}_{2}$ quadrupling and a CMIP3 composite forcing change. J Adv Model Earth Syst 8:1714-1726

Boucher O, Jones A, Betts RA (2009) Climate response to the physiological impact of carbon dioxide on plants in the Met Office Unified Model HadCM3. Clim Dyn 32:237-249 
Bretherton CS (2015) Insights into low-latitude cloud feedbacks from high-resolution models. Phil Trans R Soc A $373: 3354-3360$

Bretherton CS, Blossey PN, Jones CR (2013) Mechanisms of marine low cloud sensitivity to idealized climate perturbations: A single-LES exploration extending the CGILS cases. J Adv Model Earth Syst 5:316-337

Bretherton CS, Blossey PN, Stan C (2014) Cloud feedbacks on greenhouse warming in the superparameterized climate model SP-CCSM4. J Adv Model Earth Syst 6:1185-1204

Bony S, Bellon G, Klocke D, Sherwood S, Fermepin S, Denvil S (2013) Robust direct effect of carbon dioxide on tropical circulation and regional precipitation. Nat Geosci 6:447-451

Boucher O, Randall D, Artaxo P, et al (2014) Clouds and aerosols. In: Stocker TF, editor. Climate change 2013: the physical science basis. Contribution of working group I to the Fifth Assessment Report of the Intergovernmental Panel on Climate Change. Cambridge: Cambridge University Press, p. 571-658

Ceppi P, Brient F, Zelinka MD, Hartmann DL (2017) Cloud feedback mechanisms and their representation in global climate models. WIREs Clim Change 8:e465. doi:10.1002/wcc.465

Cess RD, Potter GL, Blanchet J (1989) Interpretation of cloud-climate feedback as produced by 14 atmospheric general circulation models. Science 245:513-516

Chadwick R, Good P, Andrews T, Martin G (2014) Surface warming patterns drive tropical rainfall pattern responses to $\mathrm{CO}_{2}$ forcing on all timescales. Geophys Res Lett 41:610-615

Chadwick R, Ackerley D, Ogura T, and Dommenget D (2018) Separating the influences of land warming, the direct $\mathrm{CO}_{2}$ effect, the plant physiological effect and SST warming on regional precipitation and circulation changes. J Geophys Res Atmos (submitted)

Chen J, Bordoni S (2016) Early summer response of the East Asian Summer Monsoon to atmospheric $\mathrm{CO}_{2}$ forcing and subsequent sea surface warming. J Clim 29:5431-5446

Chung E-S, Soden BJ (2018) On the compensation between cloud feedback and cloud adjustment in climate models. Clim Dyn 50:1267-1276

Collins WD, Ramaswamy V, Schwarzkopf MD et al (2006) Radiative forcing by well-mixed greenhouse gases: estimates from climate models in the Intergovernmental Panel on Climate Change (IPCC) fourth assessment report (AR4). J Geophys Res 111:D14317. doi:10.1029/2005JD006713

Colman R (2003) Seasonal contributions to climate feedbacks. Clim Dyn 20:825-841

Colman RA, McAvaney BJ (2011) On tropospheric adjustment to forcing and climate feedbacks. Clim Dyn 36:1649-1658

Cox PM, Betts RA, Bunton CB, Essery RLH, Rowntree PR, Smith J (1999) The impact of new land surface physics on the GCM simulation of climate and climate sensitivity. Clim Dyn 15:183-203

DeAngelis AM, Qu X, Hall A (2016) Importance of vegetation processes for model spread in the fast precipitation response to $\mathrm{CO}_{2}$ forcing. Geophys Res Lett 43:12550-12559 
Dong B, Gregory JM, Sutton RT (2009) Understanding land-sea warming contrast in response to increasing greenhouse gases. Part I: transient adjustment. J Clim 22:3079-3097

Doutriaux-Boucher M, Webb MJ, Gregory JM, Boucher O (2009) Carbon dioxide induced stomatal closure increases radiative forcing via a rapid reduction in low cloud. Geophys Res Lett 36:L02703. doi:10.1029/2008GL036273

Essery R, Best MJ, Cox PM (2001) Hadley Centre Technical Note 30: MOSES2.2 technical documentation, Tech. rep., United Kingdom Met Office, https://digital.nmla.metoffice.gov.uk/file/sdb\%3AdigitalFile\%7Cd5dbe569-5ef7-41c8-b55b-3b63dff5afbe/

Frauen C, Dommenget D, Tyrrell N, Rezny M, Wales S (2014) Analysis of the nonlinearity of El Niño Southern Oscillation teleconnections. J Clim 27:6225-6244

Gregory JM, Webb MJ (2008) Tropospheric adjustment induces a cloud component in $\mathrm{CO}_{2}$ forcing. J Clim 21:5871

Hansen J et al (2002) Climate forcings in Goddard Institute for Space Studies SI2000 simulations. J Geophys Res 107:4347. doi:10.1029/2001JD001143

He J, Soden BJ (2015) Anthropogenic weakening of the tropical circulation: the relative roles of direct $\mathrm{CO}_{2}$ forcing and sea surface temperature change. J Clim 28:8728-8742

He J, Soden BJ (2016) A re-examination of the projected subtropical precipitation decline. Nat Clim Change 7:5357

Huang Y, Tan X, Xia Y (2016) Inhomogeneous radiative forcing of homogeneous greenhouse gases. J Geophys Res Atmos 121:2780-2789

Kamae Y, Watanabe M (2012) On the robustness of tropospheric adjustment in CMIP5 models. Geophys Res Lett 39:L23808. doi:10.1029/2012GL054275

Kamae Y, Watanabe M (2013) Tropospheric adjustment to increasing $\mathrm{CO}_{2}$ : its timescale and the role of land-sea contrast. Clim Dyn 41:3007-3024

Kamae Y, Watanabe M, Kimoto M, Shiogama H (2014) Summertime land-sea thermal contrast and atmospheric circulation over East Asia in a warming climate-Part II: Importance of $\mathrm{CO}_{2}$-induced continental warming. Clim Dyn 43:2569-2583

Kamae Y, Watanabe M, Ogura T, Yoshimori M, Shiogama H (2015) Rapid adjustments of cloud and hydrological cycle to increasing $\mathrm{CO}_{2}$ : a review. Curr Clim Change Rep 1:103-113

Kamae Y, Ogura T, Shiogama H, Watanabe M (2016a) Recent progress toward reducing the uncertainty in tropical low cloud feedback and climate sensitivity: a review. Geosci Lett 3:17. doi:10.1186/s40562-016-0053-4

Kamae Y, Ogura T, Watanabe M, Xie S-P, Ueda H (2016b) Robust cloud feedback over tropical land in a warming climate. J Geophys Res Atmos 121:2593-2609 
Kawai H, Koshiro T, Webb MJ (2017) Interpretation of factors controlling low cloud cover and low cloud feedback using a unified predictive index. J Clim 30:9119-9131

Klein SA, Hartmann DL (1993) The seasonal cycle of low stratiform clouds. J Clim 6:1587-1606

Luo T, Wang Z, Zhang D, Chen B (2016) Marine boundary layer structure as observed by A-train satellites. Atmos Chem Phys 16:5891-5903

The HadGEM2 Development Team: Martin GM, Bellouin N, Collins WJ, et al. (2011) The HadGEM2 family of Met Office Unified Model climate configurations. Geosci Model Dev 4:723-757

Merlis TM (2015) Direct weakening of tropical circulations from masked $\mathrm{CO}_{2}$ radiative forcing. Proc Natl Acad Sci USA 112:13167-13171

Myers TA, Norris JR (2016) Reducing the uncertainty in subtropical cloud feedback. Geophys Res Lett 43: 2144 2148

Noda AT, Satoh M (2014) Intermodel variances of subtropical stratocumulus environments simulated in CMIP5 models. Geophys Res Lett 41:7754-7761

Norris JR (1998) Low cloud type over the ocean from surface observations. Part I: relationship to surface meteorology and the vertical distribution of temperature and moisture. J Clim 11:369-382

Ogura T, Webb MJ, Watanabe M, Lambert FH, Tsushima Y, Sekiguchi M (2014) Importance of instantaneous radiative forcing for rapid tropospheric adjustment. Clim Dyn 43:1409-1421

Qu X, Hall A, Klein SA, Caldwell PM (2014) On the spread of changes in marine low cloud cover in climate model simulations of the 21 st century. Clim Dyn 42:2603-2626

Qu X, Hall A, Klein SA, Caldwell PM (2015a) The strength of the tropical inversion and its response to climate change in 18 CMIP5 models. Clim Dyn 45:375-396

Qu X, Hall A, Klein SA, DeAngelis AM (2015b) Positive tropical marine low-cloud cover feedback inferred from cloud-controlling factors. Geophys Res Lett 42:7767-7775

Ringer MA, Andrews T, Webb MJ (2014) Global-mean radiative feedbacks and forcing in atmosphere-only and fully-coupled climate change experiments. Geophys Res Lett 41:4035-4042

Shaw TA, Voigt A (2015) Tug of war on summertime circulation between radiative forcing and sea surface warming. Nat Geosci 8:560-566

Shaw TA, Voigt A (2016) Land dominates the regional response to $\mathrm{CO}_{2}$ direct radiative forcing. Geophys Res Lett 43:11383-11391

Sherwood SC, Bony S, Boucher O, Bretherton C, Forster PM, Gregory JM, Stevens B (2015) Adjustments in the forcing-feedback framework for understanding climate change. Bull Am Meteorol Soc 96:217-228

Shine KP, Cook J, Highwood EJ, Joshi MM (2003) An alternative to radiative forcing for estimating the relative importance of climate change mechanisms. Geophys Res Lett 30:2047. doi:10.1029/2003GL018141 
Shiogama H, Watanabe M, Yoshimori M, et al (2012) Perturbed physics ensemble using the MIROC5 coupled atmosphere-ocean GCM without flux corrections: experimental design and results. Clim Dyn 39:3041-3056

Soden BJ, Broccoli AJ, Hemler RS (2004) On the use of cloud forcing to estimate cloud feedback. J Clim 17:36613665

Soden BJ, Held IM, Colman R, Shell KM, Kiehl JT, Shields CA (2008) Quantifying climate feedbacks using radiative kernels. J Clim 21:3504-3520

Sud YC, Walker GF, Lau KM (1999) Mechanisms regulating sea-surface temperatures and deep convection in the tropics. Geophys Res Lett 26:1019-1022

Sugi M, Yoshimura J (2004) A mechanism of tropical precipitation change due to $\mathrm{CO}_{2}$ increase. J Clim 17:238243

Taylor PC, Ellingson RG, Cai M (2011) Seasonal variations of climate feedbacks in the NCAR CCSM3. J Clim $24: 3433-3444$

Taylor KE, Stouffer RJ, Meehl GA (2012) An overview of CMIP5 and the experiment design. Bull Am Meteorol Soc 93:485-498

Vial J, Dufresne J-L, Bony S (2013) On the interpretation of inter-model spread in CMIP5 climate sensitivity estimates. Clim Dyn 41:3339-3362

Watanabe M, Shiogama H, Yoshimori M, Ogura T, Yokohata T, Okamoto H, Emori S, Kimoto M (2012) Fast and slow timescales in the tropical lowcloud response to increasing $\mathrm{CO}_{2}$ in two climate models. Clim Dyn 39:1627-1641

Webb MJ, Lambert FH, Gregory JM (2013) Origins of differences in climate sensitivity, forcing and feedback in climate models. Clim Dyn 40:677-707

Wood R, Bretherton CS (2006) On the relationship between stratiform low cloud cover and lower-tropospheric stability. J Clim 19:6425-6432

Wyant MC, Bretherton CS, Blossey PN, Khairoutdinov M (2012) Fast cloud adjustment to increasing $\mathrm{CO}_{2}$ in a superparameterized climate model. J Adv Model Earth Syst 4:M05001. doi:10.1029/2011MS000092

Xu KM, Li Z, Cheng A, Hu Y (2018) Changes in clouds and atmospheric circulation associated with rapid adjustment induced by increased atmospheric $\mathrm{CO}_{2}$ : a multiscale modeling framework study. Clim Dyn. doi: $10.1007 / \mathrm{s} 00382-018-4401-2$

Zhang C (1993) Large-scale variability of atmospheric deep convection in relation to sea surface temperature in the tropics. J Clim 6:1898-1913

Zelinka M, Klein S, Taylor K, Andrews T, Webb M, Gregory J, Forster P (2013) Contributions of different cloud types to feedbacks and rapid adjustments in CMIP5. J Clim 26:5007-5027

Zhou C, Zelinka MD, Klein SA (2016) Impact of decadal cloud variations on the Earth's energy budget. Nat Geosci $9: 871-874$ 
Table 1. Decomposition of climate response to quadrupling $\mathrm{CO}_{2}$ using ACCESS1.0. Simulation names in the second column refer Run I.D. in Ackerley et al. (2018). Model configuration, experimental setup, and their results are detailed in Ackerley and Dommenget (2016) and Ackerley et al. (2018)

Table 2. Responses of cloud fraction and EIS to quadrupling $\mathrm{CO}_{2}$. Values indicate 15-model ensemble means and its $95 \%$ confidence intervals. Cal \& Can column indicates area-averaged anomaly over low cloud regions off the coasts of California and the Canary Islands (Fig. 1c). SST $<27^{\circ} \mathrm{C}$ column indicate anomaly over cool ocean $\left(\mathrm{SST}<27^{\circ} \mathrm{C}\right)$ between $70^{\circ} \mathrm{S}$ and $70^{\circ} \mathrm{N}$. Winter and summer columns indicated seasonal-mean anomalies determined by May-to-September and November-to-March in the two hemispheres (see Figs. 1 and 2)

Table 3. Similar to Table 2, but for shortwave cloud radiative effect at the top of the atmosphere $\left(\mathrm{SWcld} ; \mathrm{W} \mathrm{m}^{-2}\right)$. Global column indicated global-mean anomaly including land and ocean

Table 4. Decomposed cloud, EIS and SWcld response to quadrupling $\mathrm{CO}_{2}$ averaged over cool oceans $(\mathrm{SST}<$ 
Fig. 1 Seasonality in the cloud adjustment to quadrupling $\mathrm{CO}_{2}$ simulated in $15 \mathrm{CMIP5}$ models. (a-c) Annual mean anomaly in cloud fraction over ocean (\%). (d-f) Wintertime (November-to-March in the Northern Hemisphere and May-to-September in the Southern Hemisphere, respectively) and (g-i) summertime (Mayto-September in the Northern Hemisphere and November-to-March in the Southern Hemisphere, respectively) anomalies. (a, d, g) Anomalies in total cloud fraction $\left(\Delta C_{\mathrm{t}}\right),(\mathrm{b}, \mathrm{e}, \mathrm{h})$, sum of high cloud $\left(\Delta C_{\mathrm{h}}\right)$ and middle cloud $\left(\Delta C_{\mathrm{m}}\right)$, and $(\mathrm{c}, \mathrm{f}, \mathrm{i})$ low cloud $\left(\Delta C_{1}\right)$. Stipples indicate the area where at least 12 out of 15 models agree on sign of the anomaly. Contours in (c, $\mathrm{f}, \mathrm{i})$ indicate climatological sea surface temperature (SST) of $27^{\circ} \mathrm{C}$. Boxes in (c, f, i) indicate low cloud regions off the coasts of California and the Canary Islands examined in Table 2

Fig. 2 Similar to Fig. 1, but for (a, d, g) surface air temperature ( $\triangle \mathrm{SAT}$; K), (b, e, h) air temperature at the $700 \mathrm{hPa}$ level $\left(\Delta T_{700} ; \mathrm{K}\right)$, and $(\mathrm{c}, \mathrm{f}, \mathrm{i})$ estimated inversion strength $(\Delta \mathrm{EIS} ; \mathrm{K})$, respectively

Fig. 3 (a) Zonal-mean $\triangle$ EIS (K) over cool oceans ( $\mathrm{SST}<27^{\circ} \mathrm{C}$ ). Red and blue lines indicate summertime and wintertime averages, respectively. Shading represents $95 \%$ confidential interval. (b) $\Delta C_{1}(\%)$ over cool oceans $\left(\mathrm{SST}<27^{\circ} \mathrm{C}\right)$

Fig. 4 Similar to Figs. $2 \mathrm{f}$ and $1 \mathrm{f}$, but for summertime minus wintertime anomaly

Fig. 5 Annual-mean total response to quadrupling $\mathrm{CO}_{2}$ simulated in ACCESS1.0. (a) $\Delta \mathrm{SAT}$ (K), (b) $\Delta T_{700}(\mathrm{~K})$,

(c) $\Delta \mathrm{EIS}(\mathrm{K}),(\mathrm{d}) \Delta C_{\mathrm{t}}(\%),(\mathrm{e}) \Delta C_{\mathrm{h}}+\Delta C_{\mathrm{m}}(\%)$, and (f) $\Delta C_{1}(\%)$. Contours in (f) indicate climatological SST of $27^{\circ} \mathrm{C}$

Fig. 6 Decomposed annual-mean low cloud response simulated in ACCESS1.0. (a) Effect of atmospheric radiation (RAD_ATM) on $\Delta C_{1}(\%)$. (b) Effects of plant physiological response (PLANT), (c) radiative land warming (RAD_LAND), and (d) residual (RES) 
Fig. 7 Similar to Fig. 6, but for $\Delta C_{\mathrm{h}}+\Delta C_{\mathrm{m}}(\%)$

Fig. 8 Similar to Fig. 7, but for $\Delta$ EIS (K)

Fig. 9 Wintertime and summertime response to quadrupling $\mathrm{CO}_{2}$ simulated in ACCESS1.0. (a-f) Effects of RAD_ATM and (g-l) RAD_LAND on (a, d, g, j) $\Delta T_{700}(\mathrm{~K}),(\mathrm{b}, \mathrm{e}, \mathrm{h}, \mathrm{k}) \Delta \mathrm{EIS}(\mathrm{K})$, and (c, f, i, l) $\Delta C_{1}(\%)$. Left $(a-c, g-i)$ and right panels $(d-f, j-1)$ show wintertime and summertime anomalies

Fig. 10 Similar to Fig. 3, but for effects of (a, b) RAD_ATM and (c, d) RAD_LAND to (a, c) $\Delta$ EIS (K) and (b, d) $\Delta C_{1}(\%)$ simulated in ACCESS1.0

Fig. 11 Effect of RAD_ATM to vertical motion and temperature advection. (a) Wintertime and (c) summertime anomaly in pressure velocity $\left(\omega ; \mathrm{hPa}_{\text {day }}{ }^{-1}\right)$ at the $700 \mathrm{hPa}$ level $\left(\Delta \omega_{700}\right)$. Solid and dashed contours represent climatological $\omega_{700}$ of $10 \mathrm{hPa}$ day $^{-1}$ (downward) and $-10 \mathrm{hPa} \mathrm{day}^{-1}$ (upward), respectively. (b) Wintertime and (d) summertime vertical temperature advection and adiabatic compression $\left(\mathrm{K}\right.$ day $\left.^{-1}\right)$ at the $700 \mathrm{hPa}$ level. (e) Zonal-mean vertical temperature advection and adiabatic compression $\left(\mathrm{K} \mathrm{day}^{-1}\right)$ at the $700 \mathrm{hPa}$ level (blue: winter, red: summer) averaged over cool oceans (SST $<27^{\circ} \mathrm{C}$ )

Fig. 12 Comparison of instantaneous radiative heating due to quadrupling $\mathrm{CO}_{2}$ among five climate models. (a-e) Wintertime radiative heating $\left(\mathrm{K} \mathrm{day}^{-1}\right)$ at the $700 \mathrm{hPa}$ level and $(\mathrm{f}-\mathrm{j})$ summertime minus wintertime radiative heating simulated in (a, f) CanAM4, (b, g) HadGEM2-A, (c, h) IPSL-CM5A-LR, (d, i) MIROC3, and (e, j) 
Table 1.

\begin{tabular}{|c|c|c|}
\hline Name & Definition & Explanation \\
\hline TOTAL & $\mathrm{A} 4 \mathrm{x}-\mathrm{A}$ & Total effect of $4 \mathrm{xCO}_{2}$ \\
\hline RAD_ATM & $\mathrm{A} 4 \mathrm{xrad}_{\mathrm{PL}}-\mathrm{A}_{\mathrm{PL}}$ & Effect of atmospheric radiation \\
\hline RAD_LAND & $A_{P L 4 x r a d}-A_{P L}$ & Effect of radiative land warming \\
\hline P_PLANT & $\mathrm{A} 4 \mathrm{x}_{\mathrm{PL}}-\mathrm{A} 4 \mathrm{xrad}_{\mathrm{PL}}$ & $\begin{array}{l}\text { Effect of plant physiological response } \\
\text { except soil moisture and soil temperature }\end{array}$ \\
\hline P_LAND & $A_{P L 4 x}-A_{P L 4 x r a d}$ & $\begin{array}{l}\text { Effect of plant physiological response via } \\
\text { soil moisture and soil temperature }\end{array}$ \\
\hline PLANT & P_PLANT + P_LAND & $\begin{array}{c}\text { Total effect of plant physiological } \\
\text { response }\end{array}$ \\
\hline RES & $\begin{array}{l}\text { TOTAL }-(\text { RAD_ATM }+ \\
\text { RAD_LAND }+ \text { PLANT })\end{array}$ & Residual \\
\hline
\end{tabular}


Table 2.

\begin{tabular}{l|ccc|ccc}
\hline & \multicolumn{3}{|c|}{ Cal \& Can } & \multicolumn{3}{c}{ SST $<27^{\circ} \mathrm{C}$} \\
& Annual & Winter & Summer & Annual & Winter & Summer \\
\hline$\Delta C_{t}(\%)$ & $-0.63 \pm 0.40$ & $-0.84 \pm 0.36$ & $-0.27 \pm 0.50$ & $-0.58 \pm 0.34$ & $-0.94 \pm 0.33$ & $-0.18 \pm 0.41$ \\
$\Delta C_{h}+\Delta C_{m}(\%)$ & $-1.19 \pm 0.25$ & $-0.79 \pm 0.23$ & $-1.59 \pm 0.32$ & $-0.91 \pm 0.21$ & $-0.74 \pm 0.21$ & $-1.07 \pm 0.24$ \\
$\Delta C_{l}(\%)$ & $0.21 \pm 0.26$ & $-0.46 \pm 0.31$ & $1.03 \pm 0.35$ & $-0.00 \pm 0.22$ & $-0.61 \pm 0.27$ & $0.71 \pm 0.25$ \\
$\Delta$ EIS (K) & $0.41 \pm 0.10$ & $0.08 \pm 0.08$ & $0.77 \pm 0.13$ & $0.28 \pm 0.05$ & $0.12 \pm 0.05$ & $0.46 \pm 0.05$ \\
\hline
\end{tabular}

595 
Table 3.

\begin{tabular}{l|ccc|ccc}
\hline & \multicolumn{3}{|c|}{ Global } & \multicolumn{3}{c}{$\mathrm{SST}<27^{\circ} \mathrm{C}$} \\
& Annual & Winter & Summer & Annual & Winter & Summer \\
\hline$\Delta \mathrm{SWcld}\left(\mathrm{W} \mathrm{m}^{-2}\right)$ & $1.09 \pm 0.49$ & $1.07 \pm 0.35$ & $1.09 \pm 0.66$ & $1.17 \pm 0.51$ & $1.25 \pm 0.39$ & $1.07 \pm 0.70$ \\
\hline
\end{tabular}




\begin{tabular}{lcccc}
\hline & & Annual & Winter & Summer \\
\hline \multirow{4}{*}{$\Delta C_{t}(\%)$} & TOTAL & -0.02 & -0.53 & 0.71 \\
& RAD_ATM & -0.11 & -0.52 & 0.37 \\
& RAD_LAND & 0.15 & -0.01 & 0.35 \\
& PLANT & -0.13 & -0.06 & -0.14 \\
& RES & 0.07 & 0.06 & 0.12 \\
\hline \multirow{4}{*}{$\Delta C_{l}(\%)$} & TOTAL & 1.05 & 0.43 & 1.89 \\
& RAD_ATM & 0.68 & 0.17 & 1.26 \\
& RAD_LAND & 0.41 & 0.08 & 0.75 \\
& PLANT & -0.21 & -0.01 & -0.38 \\
& RES & 0.18 & 0.19 & 0.26 \\
\hline \multirow{4}{*}{$\Delta$ EIS $(\mathrm{K})$} & TOTAL & 0.32 & 0.16 & 0.53 \\
& RAD_ATM & 0.25 & 0.15 & 0.38 \\
& RAD_LAND & 0.11 & 0.05 & 0.18 \\
& PLANT & -0.02 & 0.03 & -0.07 \\
& RES & 0.01 & -0.03 & 0.07 \\
\hline TSWcld $\left(\mathrm{W} \mathrm{m}{ }^{-2}\right)$ & ROTAL & 0.55 & 0.75 & 0.17 \\
& RAD_ATM & 0.66 & 0.73 & 0.49 \\
& PLANAND & -0.26 & -0.04 & -0.57 \\
& RES & 0.20 & 0.12 & 0.30 \\
& & -0.05 & -0.06 & -0.05 \\
\hline
\end{tabular}

601 
603
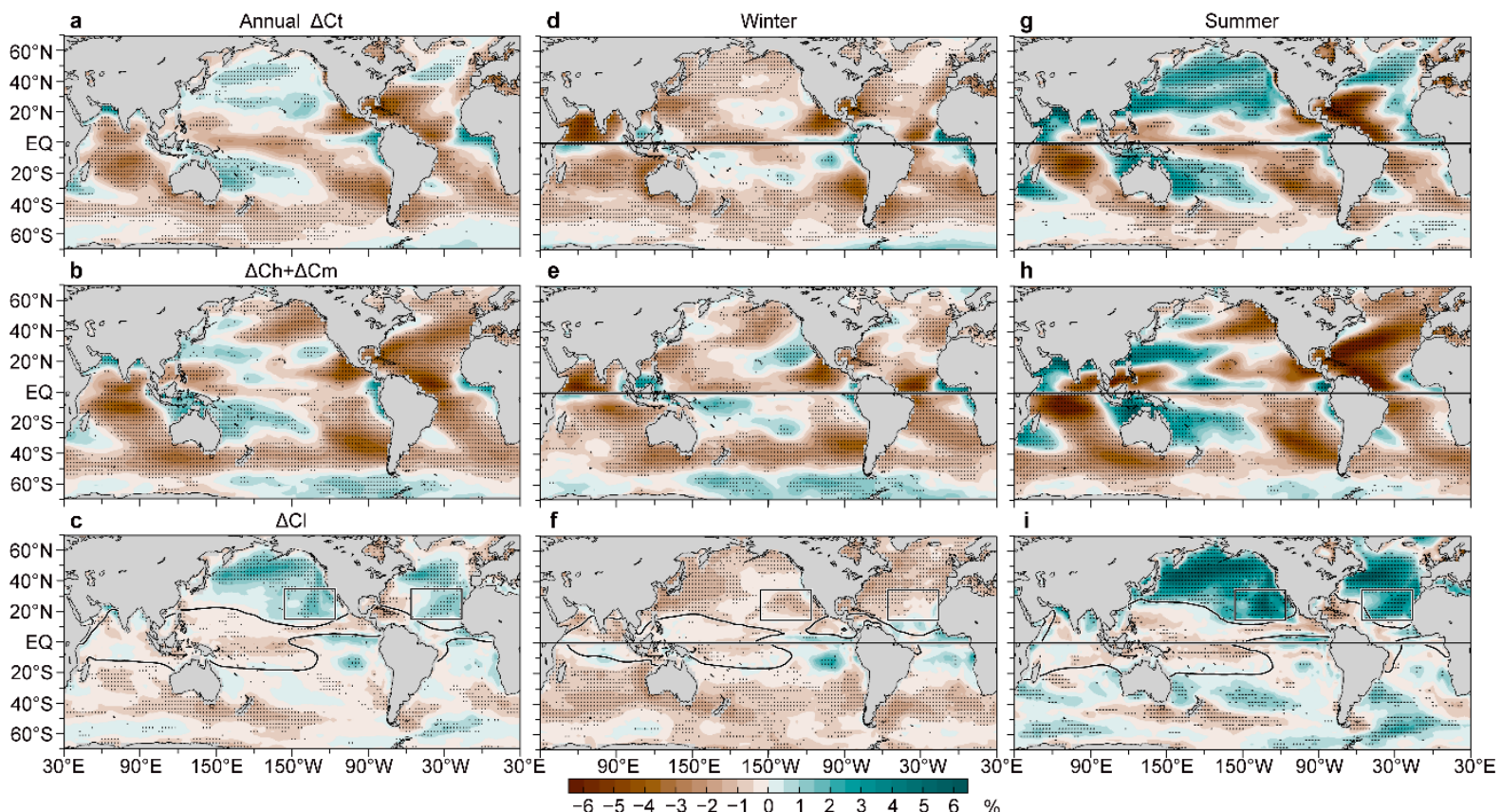

604

605

606

Fig. 1

607 

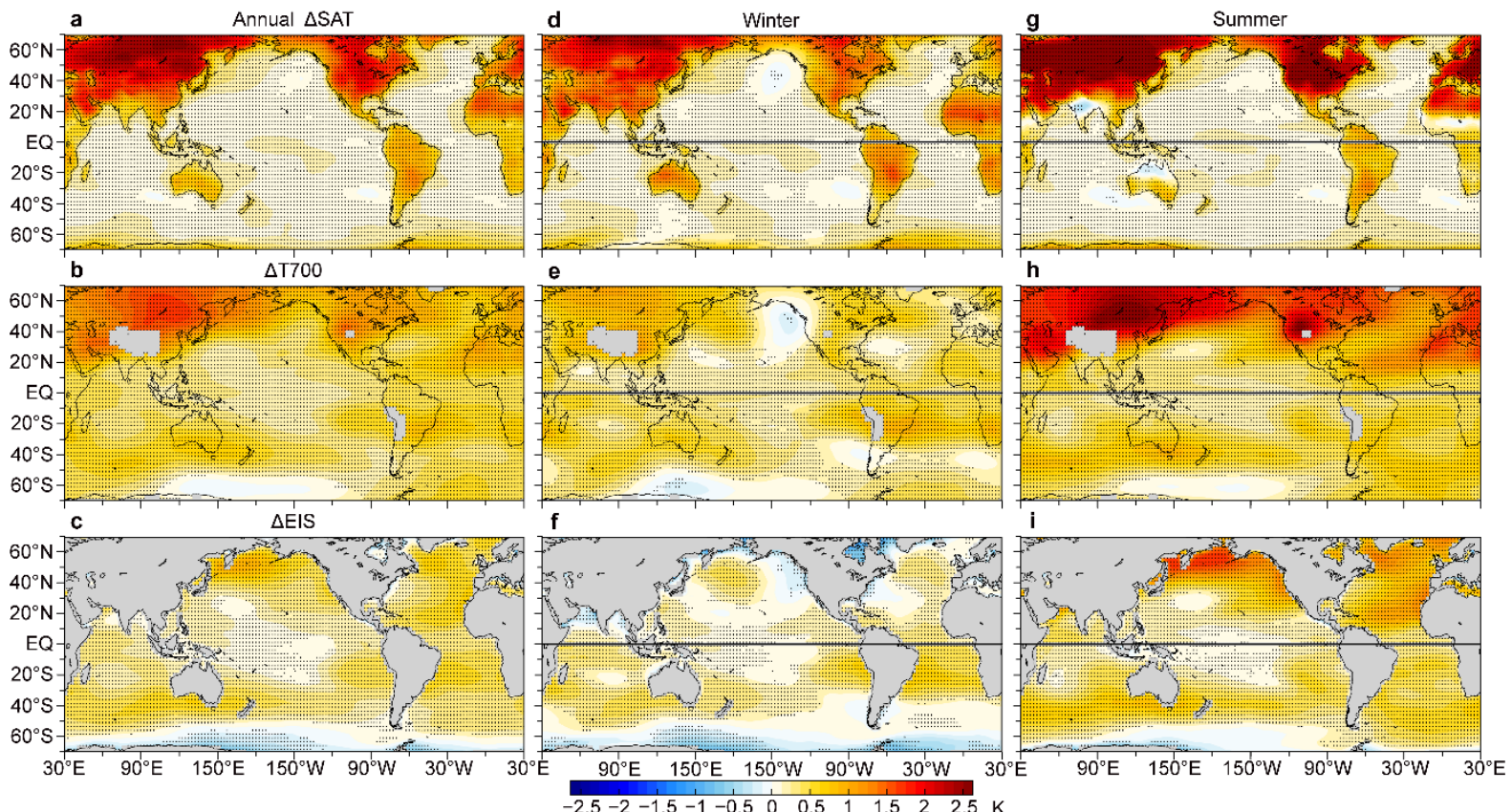

Fig. 2 


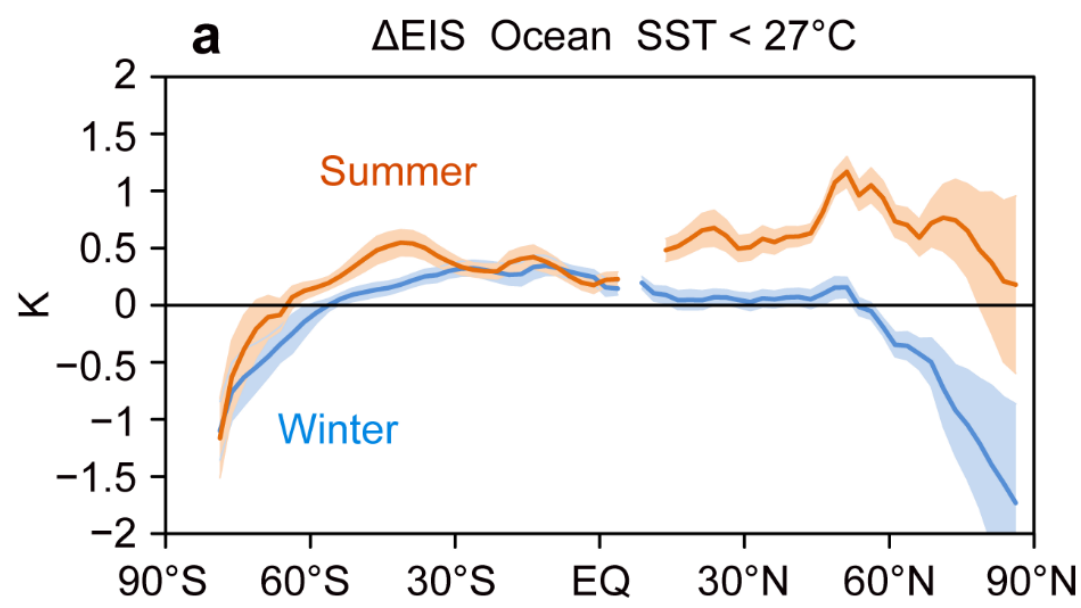

612

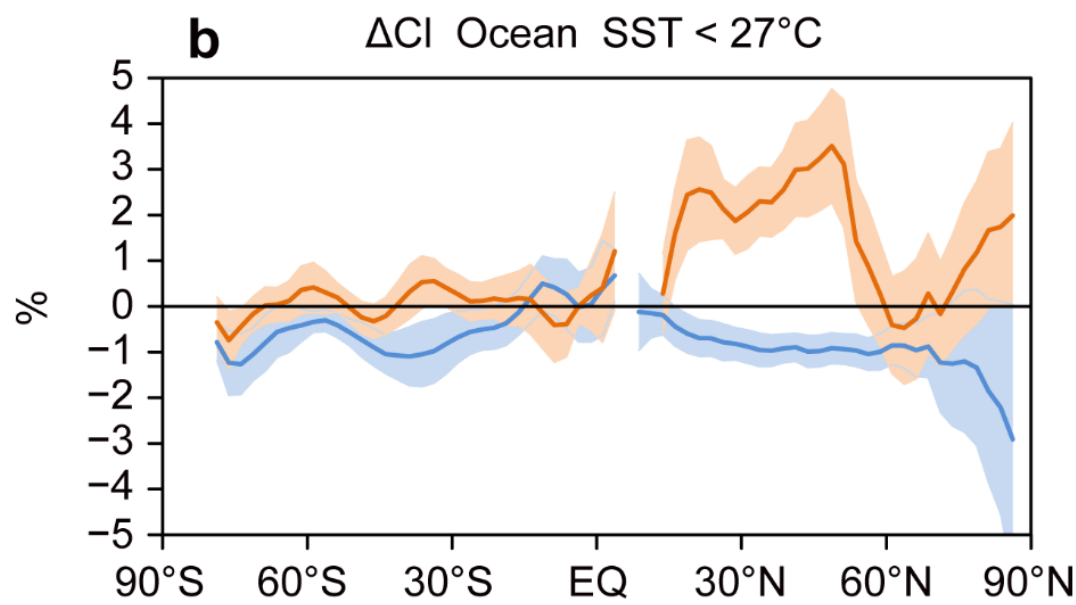

613

614 Fig. 3

615

616 

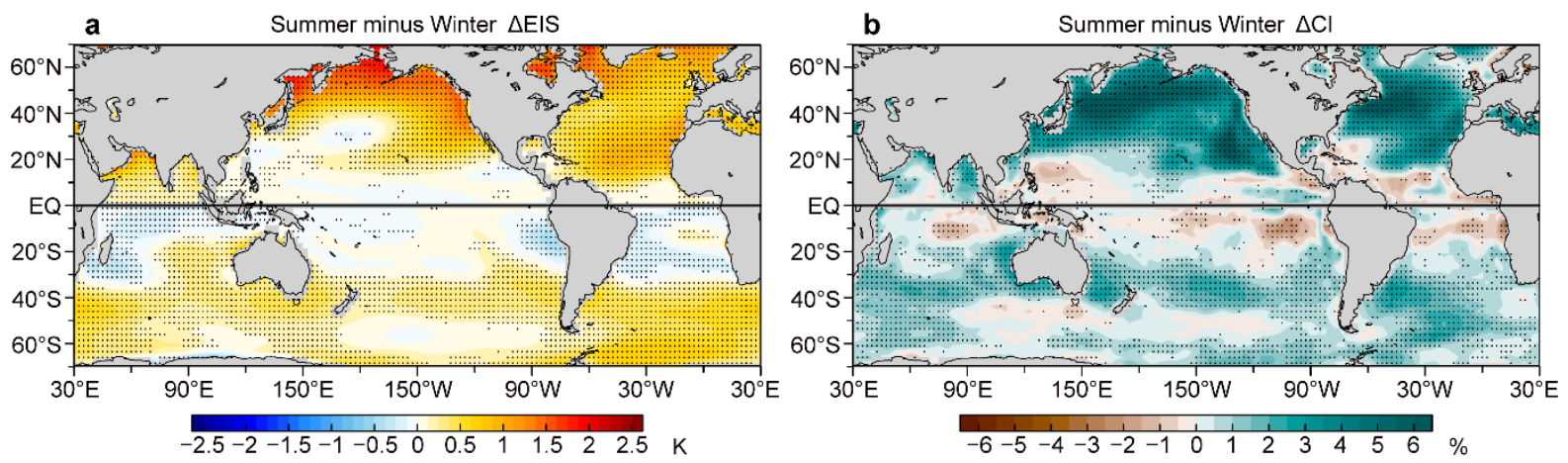

617

618

$619 \quad$ Fig. 4

620 

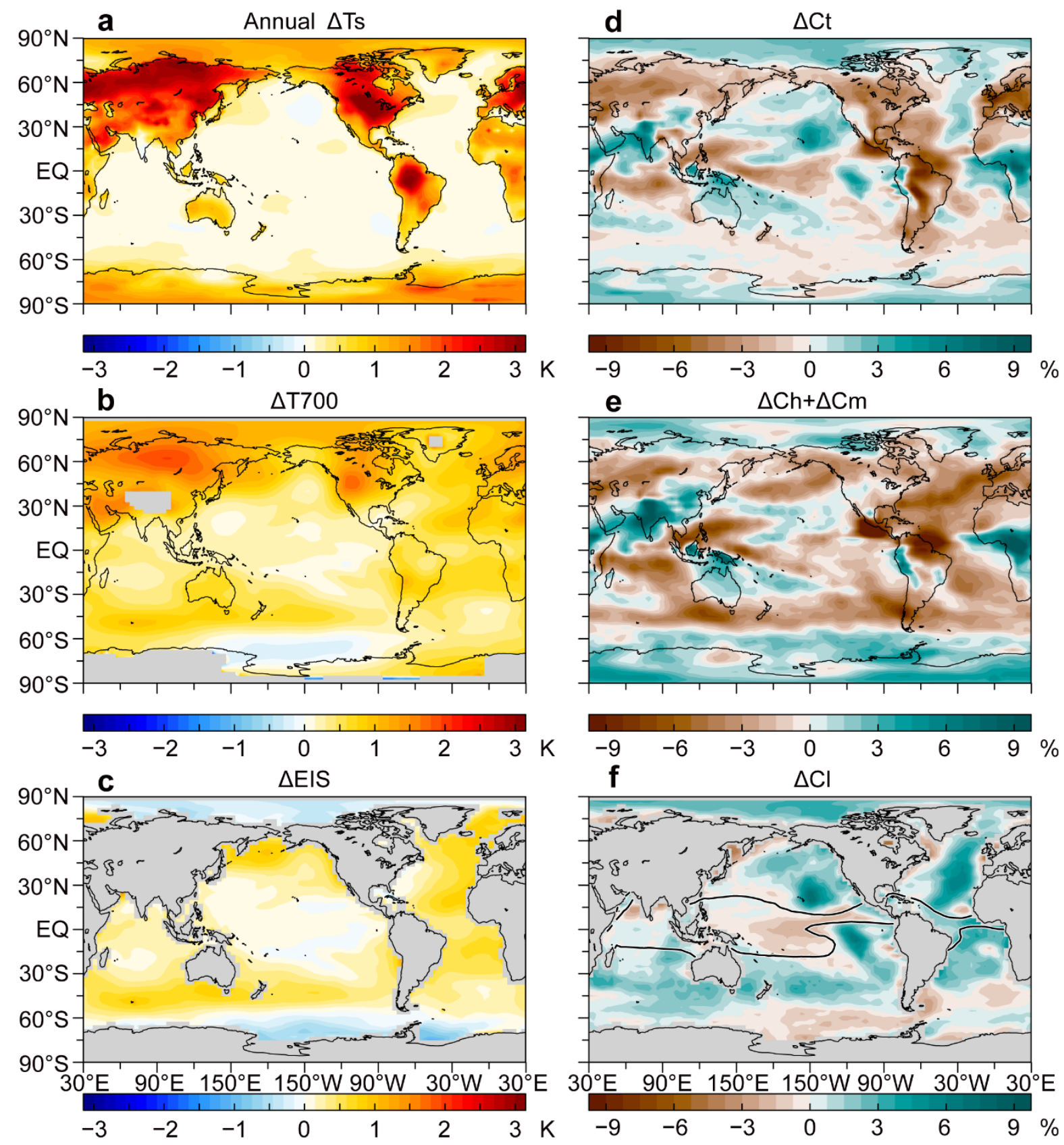

Fig. 5 

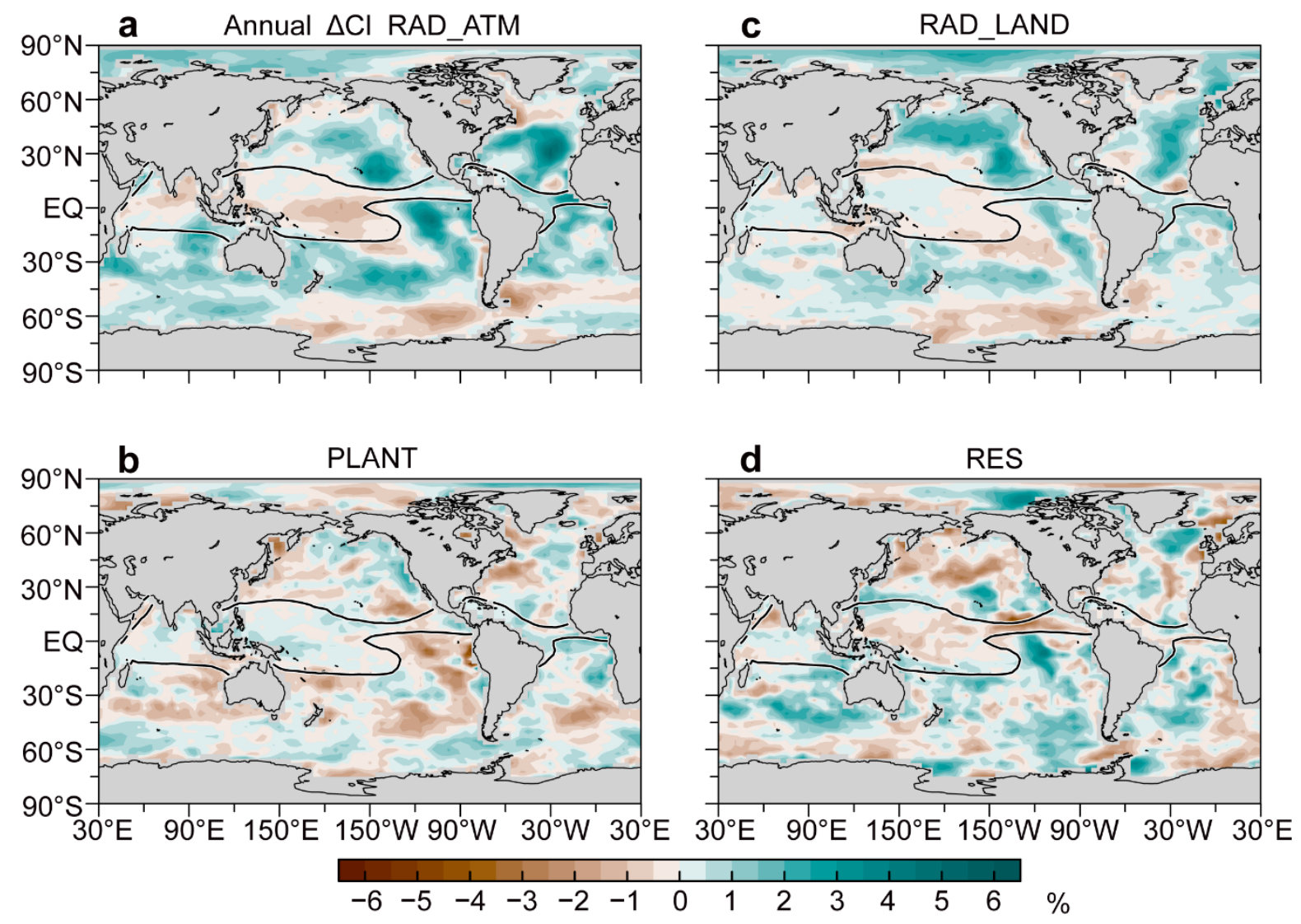

Fig. 6

627 

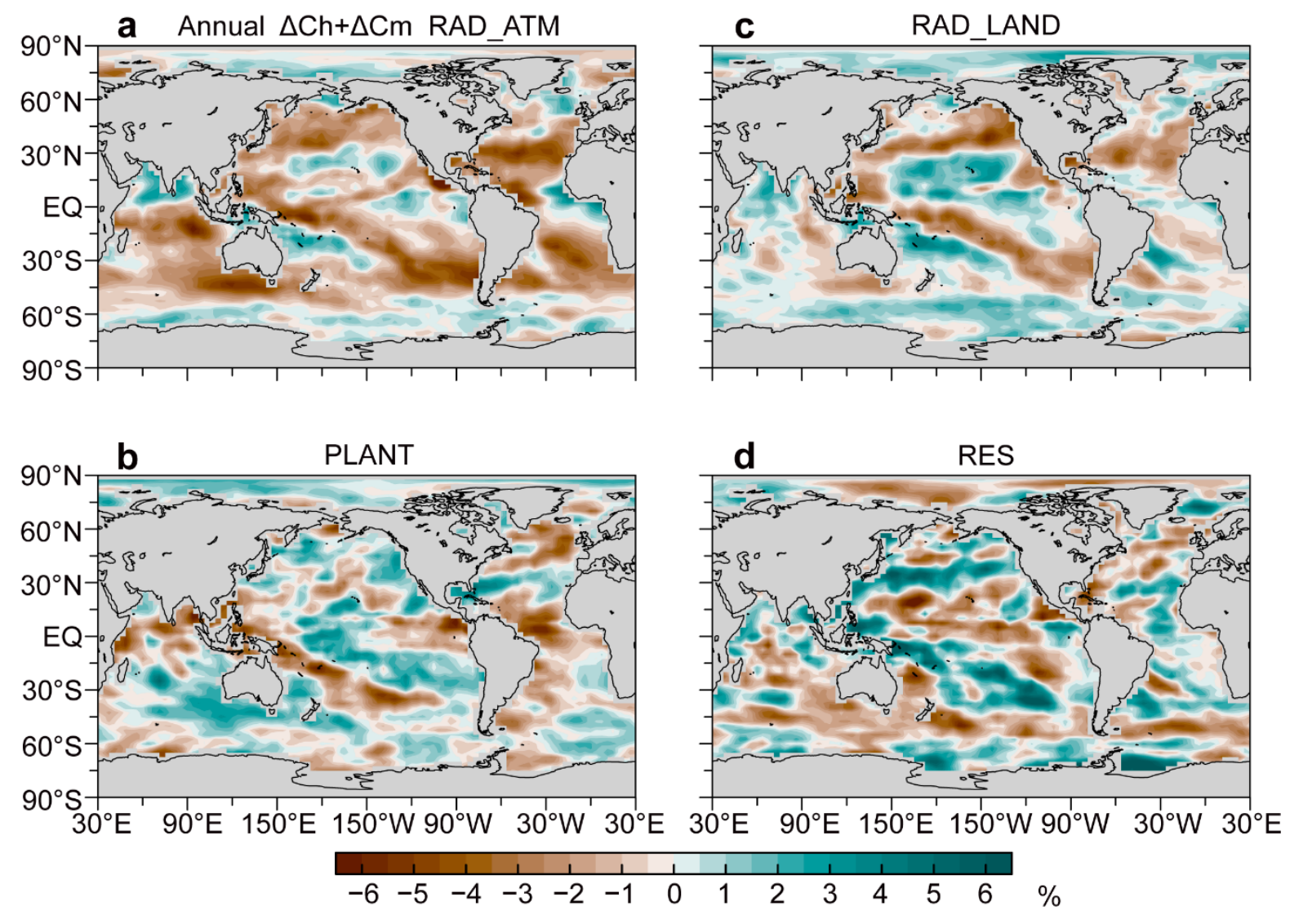

Fig. 7 

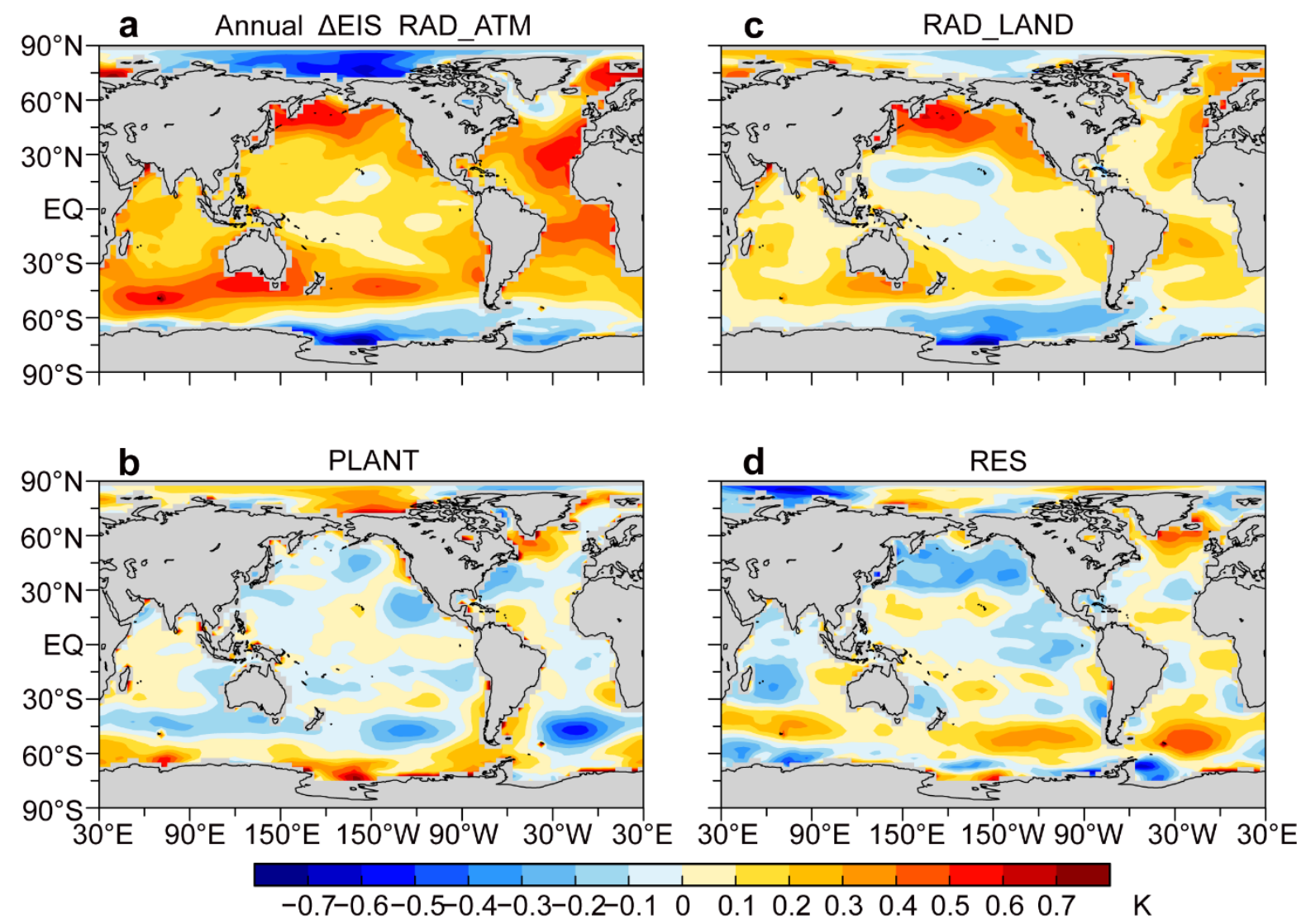

Fig. 8 

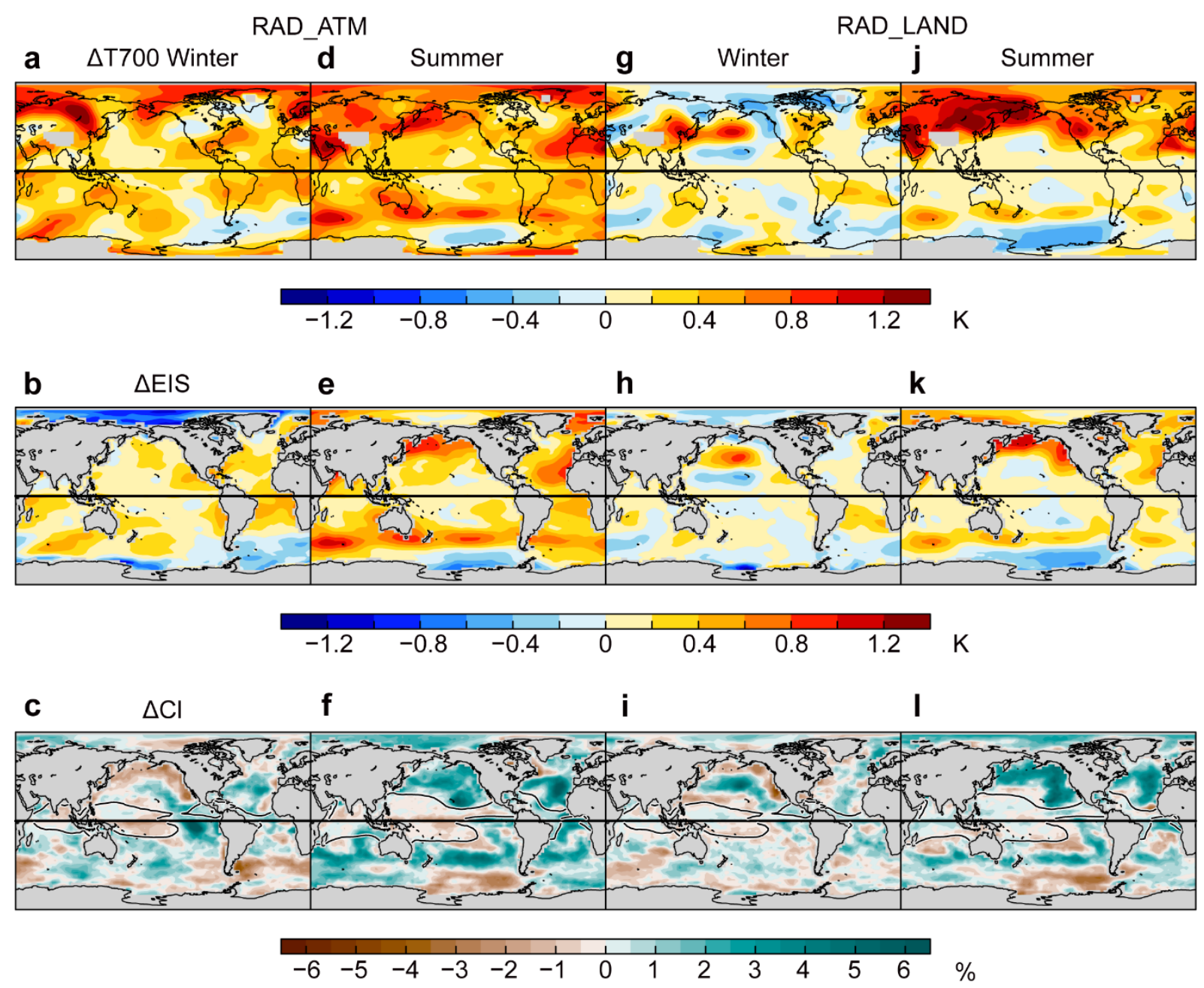

Fig. 9

639 


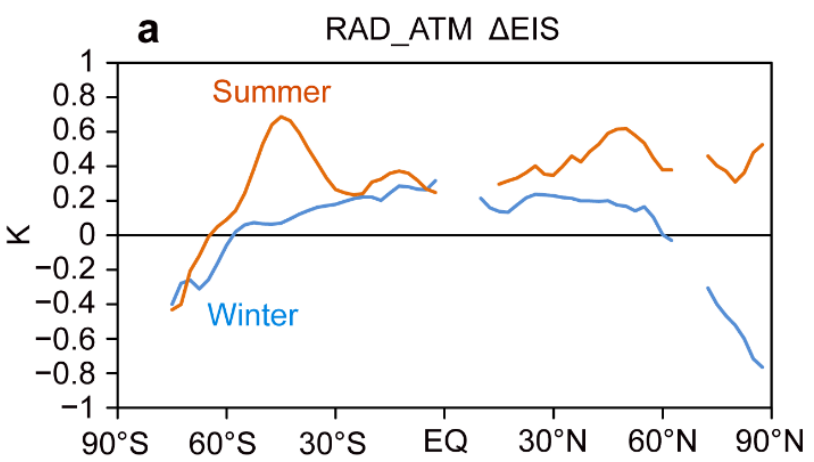

c RAD_LAND $\triangle E I S$
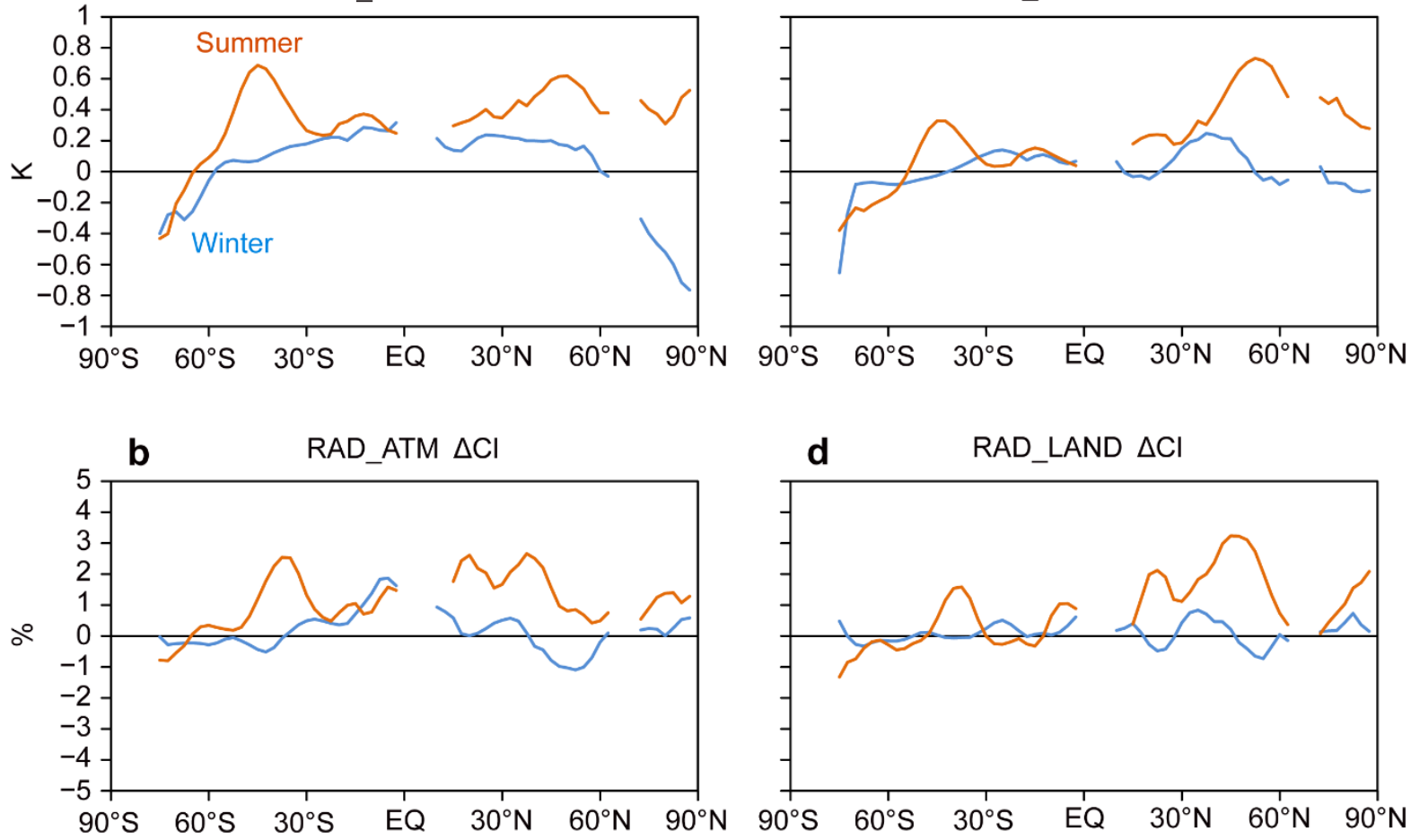

641

642

Fig. 10

643 

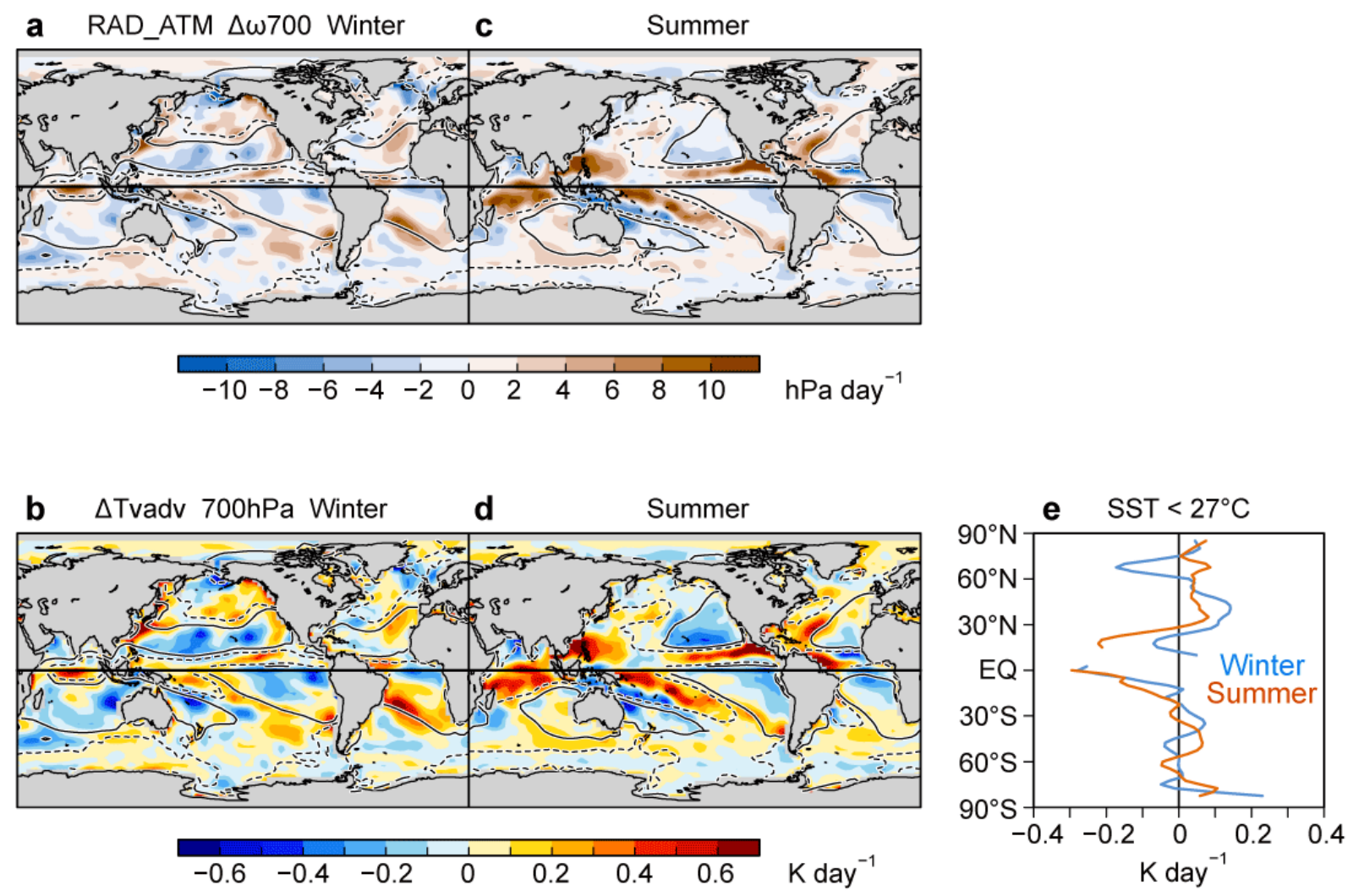

644

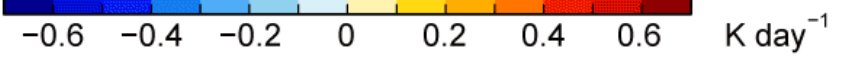

Fig. 11

647 

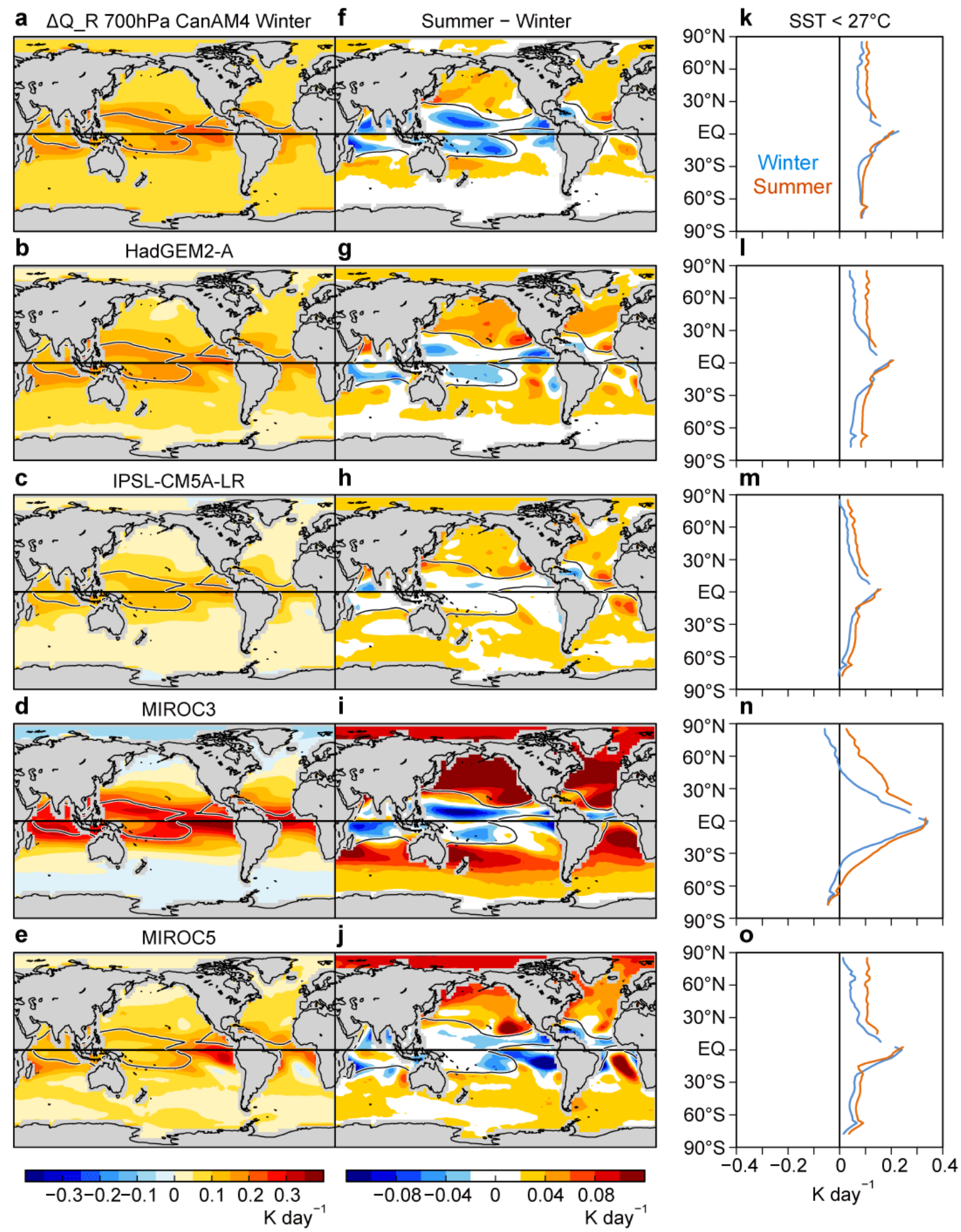